\title{
Capacities of \\ Plumbing Stacks in Buildings
}

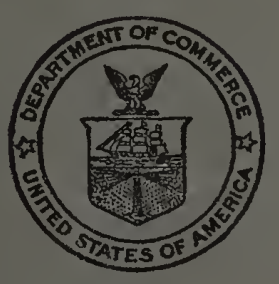

United States Department of Commerce National Bureau of Standards

Building Materials and Structures Report 132 


\section{BUILDING MATERIALS AND STRUCTURES REPORTS}

On request, the Superintendent of Documents, U. S. Government Printing Office, Washington $25, \mathrm{D}$. C., will place your name on a special mailing list to receive notices of new reports in this series as soon as they are issued. There will be no charge for receiving such notices.

An alternative method is to deposit with the Superintendent of Documents the sum of $\$ 5$, with the request that the reports be sent to you as soon as issued, and that the cost thereof be charged against your deposit. This will provide for the mailing of the publications without delay. You will be notified when the amount of your deposit has become exhausted.

If 100 copies or more of any report are ordered at one time, a discount of 25 percent is allowed. Send all orders and remittances to the Superintendent of Documents, U. S. Government Printing Office, Washington $25, D . C$.

The following publications in this series are available by purchase from the Superintendent of Documents at the prices indicated:

BMS2 Methods of Determining the Structural Properties of Low-Cost House Constructions_-

BMS3

BMS4

BMS5

BMS6

BMS8

BMS9

Suitability of Fiber Insulating Lath as a Plaster Base

Accelerated Aging of Fiber Building Boards .

Structural Properties of Six Masonry Wall Constructions

Survey of Roofing Materials in the Southeastern States

Methods of Investigation of Surface Treatment for Corrosion Protection of Steel.structions for Walls, Partitions, Floors, and Roofs.

BMS10 Structural Properties of One of the "Keystone Beam Steel Floor" Constructions Sponsored by the H. H. Robertson Co...

BMS11 Structural Properties of the Curren Fabrihome Corporation's "Fabrihome" Construc-

BMS12 Structural Properties of "Steelox" Constructions for Walls, Partitions, Floors, and Roofs Sponsored by Steel Buildings, Inc. . . .

BMS14 Indentation and Recovery of Low-Cost Floor Coverings
BMS15 Structural Properties of "Wheeling Long-Span Steel Floor" Construction Sponsored by

BMS16 Structural Properties of a "Tilecrete" Floor Construction Sponsored by Tilecrete Floors, Inc.-

BMS17 Sound Insulation of Wall and Floor Constructions

Supplement to BMS17, Sound Insulation of Wall and Floor Constructions Supplement No. 2 to BMS17, Sound Insulation of Wall and Floor Constructions........ BMS18 Structural Properties of "Pre-fab" Constructions for Walls, Partitions, and Floors

BMS20 Structural Properties of "Twachtman" Constructions for Walls and Floors Sponsored

BMS21 Structural Properties of a Concrete-Block Cavity-Wall Construction Sponsored by the

BMS22 Structural Properties of "Dun-Ti-Stone" Wall Construction Sponsored by the Brick

BMS23 Structural Properties of a Brick Cavity-Wall Construction Sponsored by the W. E.

BMS24 Structural Properties of a Reinforced-Brick Wall Construction and a Brick-Tile CavityWall Construction Sponsored by the Structural Clay Products Institute-

BMS25

Structural Properties of Conventional Wood-Frame Constructions for Walls, Partitions, Floors, and Roofs "Neleon Pre-Cast Concrete Foundation" Wall Construction.

BMS26 Sponsored by the Nelson Cement Stone Co., Inc

BMS27 Structural Properties of "Bender Steel Home" Wall Construction Sponsored by the Bender Body Co.

BMS28

BMS29

BMS30

Backfiow Prevention in Over-Rim Water Supplies

Survey of Roofing Materials in the Northeastern States

Structural Properties of a Wood-Frame Wall Construction Sponsored by the Douglas

BMS32 Structural Properties of Two Brick-Concrete-Block Wall Constructions and a Concrete-Block Wall Construction Sponsored by the National Concrete Masonry Association. Wall Construction Sponsored by the National Concrete Masonry

BMS33

BMS34

Plastic Calking Materials $10 \%$ 


\section{Capacities of \\ Plumbing Stacks in Buildings}

Robert S. Wyly and Herbert N. Eaton

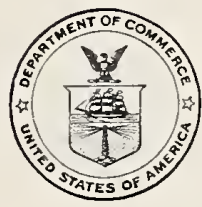

Building Materials and Structures Report 132

Issued May 28, 1952 


\section{Foreword}

The problem of what constitutes the capacity of a vertical plumbing drainage stack in a building has never been solved satisfactorily. The lack of knowledge in this respect is reflected in the glaring differcnces in stack-loading tables found in different plumbing codes. Obviously no building drainage system can be designed economically unless the minimum sizes of pipes that can be used in its various parts can be predicted, and this is particularly true of the drainage stack and the building drain as these are the largest pipes used in the system. Attempts have been made for many years to solve the problem, but, owing to the complexity of the flow phenomena in the drainage system, progress has been made only with the conditions so simplified that the practical utility of the results is very restricted.

The investigation reported here was an attempt to solve one of the more complicated problems of stack capacities - the maximum load that can be brought into the stack from a horizontal branch when water is being discharged down the stack from fixtures on higher floors. A theoretical approach to the problem was used, and the resulting formula was tested by experiment. As a result, a distinct step forward has been made in the solution of the problem.

The research forming the basis of this report was undertaken for the Housing and Home Finance Agency as part of the research program of that Agency under its statutory authority. The report presents only the results of the first part of the investigation.

\section{A. V. Astin, Acting Director.}

\section{Contents}

Foreword

1. Introduction

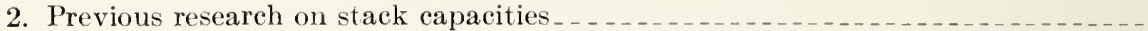

2.1. National Bureau of Standards

2.2. State University of Iowa

3. Summary of attempts to define stack capacity
3.1. National Bureau of Standards

3.2. State University of Iowa $\quad$ University of Illinois

4. The problem of stack capacity

4.1. Basic factors to be considered $\ldots \ldots \ldots$ a. Noise and vibration.

b. Excessive pressures in horizontal branches $\ldots \ldots$

4.2. Tentative definition of stack capacity

4.3. Terminal velocity and terminal length

5. Terminal velocities in stacks _.

5.1. Tests at the National Bureau of Standards --1

5.2. Tests at the State University of Iowa

5.3. Derivation of equation for terminal velocifies

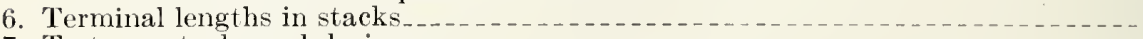

7. Tests on stacks and drains

7.1. Nature of the tests two horizontal branches and a vertical stack

8. Analysis of conditions at the stack fitting where a horizontal drain empties into a stack at an intermediate floor of a multistory building

8.1. Statement of the problem

8.2. Analysis of the problem

9. Summary _

10. Application of the results of the investigation

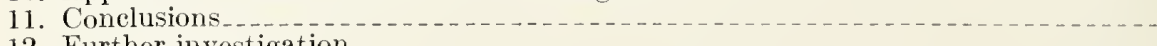

12. Further investigation $\ldots$

13. References Appendix. Evaluation of the sand roughness coefficient, $k_{5}$ 


\title{
Capacities of Plumbing Stacks in Buildings
}

\author{
Robert S. Wyly and Herbert N. Eaton
}

\begin{abstract}
This report gives the results of the first phase of a theoretical and experimental investi gation of the capacities of plumbing drainage stacks in buildings. Because of the complexity of the problem and the wide variety of conditions that are encountered in providing sanitary drainage for buildings, no satisfactory means of determining the sizes of pipes required in the drainage system of a particular building has ever been developed. The present investigation was intended to solve one of the problems involved in determining the capacity of a vertical drainage stack, namely, the pressures that are produced in a horizontal drain by the interference of the flow down the stack from higher levels with the flow from a horizontal drain into the stack at some intermediate level. This was accomplished by developing an equation for the relation between rate of flow down the stack, rate of flow from the branch, pneumatic pressures in the stack and in the branch at the branch level under consideration, the diameters of the stack and the branch, and the backpressure produced in the branch. With the aid of experiment, the unknown quantities in the equation were determined, and the equation can be used to predict this backpressure for any given conditions when a sanitary tee stack fitting is used to connect the branch to the stack.
\end{abstract}

\section{Introduction}

The soil, or waste, stack of a building is the vertical drainage pipe into which the horizontal branches carrying the discharge of the fixtures empty and which carries the waste water down to the building drain. Above the lighest fixture connection on the stack, the stack continues upward througl the roof, sometimes with, sometimes without change in diameter, to serve as a vent for the stack. This portion of the stack is called the stack vent, and the portion above the roof is frequently referred to as the roof vent.

The hydraulic and pneumatic conditions existing in such a stack down which water is flowing are extremely complicated. The stack flows only partly full, the water tending to form an annular sheet around the wall of the stack. A considerable quantity of air is carried along witl the water, this air entering the system through the various vent pipes, including the stack vent. When the sheet of water reaches the bottom of the stack, it flows around the bend, frequently still adhering to the wall around its entire circumference, falling away from the upper part of the cross section onty after it has traveled a short distance. In the lower portion of the stack there is a tendency for positive pneumatic pressures to exist; hence considerable quantities of air are removed from this portion of the stack through any vent pipes that are connected to the stack in this region of positive pressure, that is, pressures greater than atmospheric pressure.

The water entering the building drain from the stack is traveling at a higher velocity than can be maintained in a sloping building drain by the force of gravity. The result is that the stream slows up gradually, until finally, if the drain is long enough, it suddenly increases in depth and decreases in velocity, forming what is called a hydraulic jump [1], ${ }^{1}$ which may or may not entirely fill the cross section of the drain at the section at which it occurs. If the hydraulic jump fills the entire cross section of the pipe, this forms a barrier to the further travel of the air that is moving with the water, and the pneumatic pressure in the drain upstream from this section and in the lower part of the stack increases, gradually returning to its normal value, somewhere near atmospheric pressure, in about one story height or thereabouts, in the usual multistory installation.

If the water is flowing down the stack in the form of an annular sheet at a particular floor level, coming from fixtures on higher floors, and, if water is also flowing out of a horizontal branch at that floor level, the stream from the branch interferes with the flow down the stack, with the result that a backpressure is created in the branch, and, if the system is not properly designed, this backpressure may be enough to flood shower stalls or to produce sluggish flow from fixtures emptying into the branch, or to affect the proper functioning of vents connecting into the branch.

Where the flow from a horizontal branch enters the stack, it may fill the entire cross section of the stack if the flow is large enough. As the velocity of the water thus entering the stack increases downward under the influence of gravity, the pressure in the stack in this region decreases, sometimes very greatly, gradually returning to its normal value, which is approximately atmospheric pressure, usually within a distance equal to one to three stories' height of the building.

When the building drain includes a house trap, and when the discharge from a water closet or some other fixture closes off the cross section of the stack at some point, air is thus trapped between

1 Numbers in brackets indicate the references at the end if this report. 
the two water seals, and, owing to the fact that water is flowing into the space containing the trapped air for several seconds before an equal flow passes out through the house trap, some of the trapped air must be displaced. This frequently results in blowing the fixture trap seals in lines connecting into the stack between the two water seals referred to. This phenomenon has been observed in tests.

The large amount of air that is carried down a stack with the water is not generally recognized. As a very rough approximation, we may say that about as much air as water by volume, is carried down the stack, although in some instances the air flow will greatly exceed the water flow. This air must come from somewhere, usually from the stack vent, but if the cross section is closed off at some point by the discharge from a horizontal branch, then it must come in part from the horizontal branches, and, if the venting system is inadequate, this results in pulling the seals of fixture traps. In regions of positive pressure, inadequate venting results in the blowing of trap seals.

Because of the extreme complexity of the hydraulic and pneumatic conditions existing in the sanitary drainage systems of buildings, little progress has been made toward the establishment of any sound basis for determining how great a load can be imposed on a given system without impairing the adequacy of its operation. Rather we have learned from experience what a system of a given size will stand, and loading tables for plumbing drainage stacks have been established, mainly on the basis of this experience. The great variation in permissible loadings on stacks can be seen from table 1 .

TABLE 1. Maximum fixture-unit loadings on multistory stacks permitted by different authorities

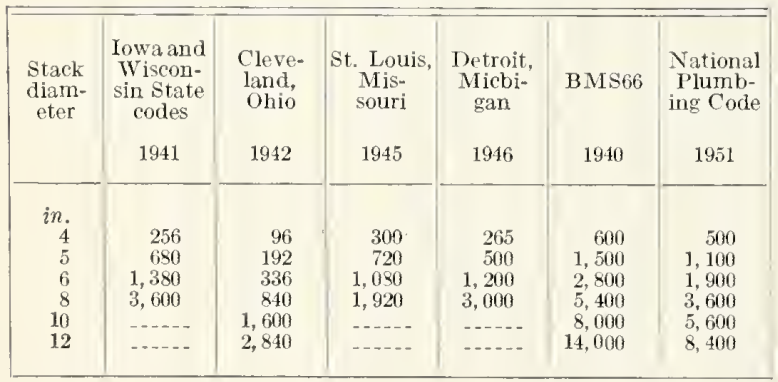

From table 1 it is obvious that there has been little or no agreement as to what constitutes maximum permissible loadings on multistory stacks. Similar disagreement exists regarding loads on short stacks, horizontal branches, building drains, and building sewers, storm and combined drains and sewers, and vents. In terms of actual fixtures, or groups of fixtures, the variation in permissible loadings on stacks is not always as great as indicated by table 1 , owing to the fact that fixture-unit ratings for some fixtures are assigned different values by different codes. In this connection, table 2 shows the fixture-unit values for water closets employed in the codes listed in table 1.

TABLE 2. Fixture-unit values for water closets according to different authorities (as applied to drainage loads)

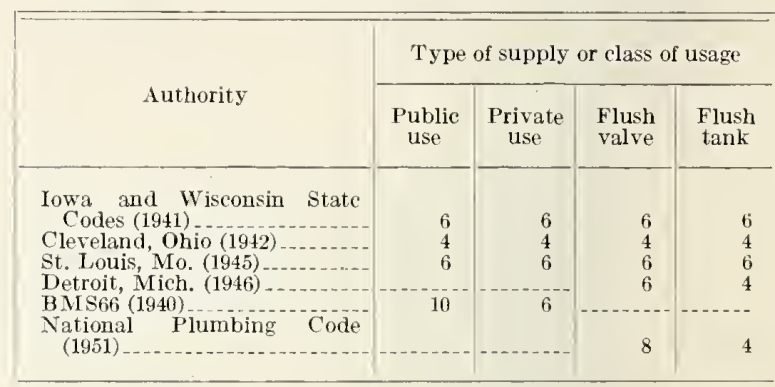

\section{Previous Research on Stack Capacities}

Several attempts have been made in the past to obtain some knowledge of the flow and pressure conditions in stacks and thus to ofler, at least to some extent, a solid basis for establishing tables of stack loadings. This has been very difficult, for not enough has been known about the conditions in stacks to permit a satisfactory definition of stack capacities to be proposed. 'T he late Roy B. Hunter at the National Bureau of Standards, F. M. Dawson and A. A. Kalinske at the State University of Iowa, and Harold E. Babbitt at the University of Illinois, have all made contributions to the subject.

\subsection{National Bureau of Standards}

Hunter first reported tests on stack capacities in 1923 [2]. In his report are to be found some of the first clear statements regarding the nature of flow in partly filled stacks and the first definition of stack capacity that the authors of this paper have found. The following is quoted from Hunter's report:

The character of the flow of water in partially filled vertical pipes varies with the extent to which the pipe is filled. $* * *$ For small volumes of flow, amounting to little more than a trickle, the flow is entirely on the inner wall of the stack. With increase in volume, this adherence of the flow to the wall continues up to the point where the frictional resistance of the air causes it to diaphragm across the pipe, temporarily forming a short slug of water which descends as a slug filling the stack until increased air pressure breaks through, the water forming the slug either being thrown against the wall or falling a short distance as separate streamlets in the center of the pipe. This diaphragming and forming slugs probably first appears in a 3-in. stack when the stack is from one-fourth to one-third full. As the volume of flow increases, the slugs thus formed are more frequent and more persistent, and in a stack open at the lower end may not be broken through. This intermittent rate partially accounts for the rapid erratic oscillations of pressure in a plumbing system.

With regard to stack capacity and fitting capacity, Hunter wrote as follows: 
In vertical stacks a static head can develop only after the stack has becone filled at some point. With the water introduced at a given rate by volume, this will first occur at the point of lowest velocity, evidently at the point of entrance. Since the vertical component of the entrance velocity is less than the maximum velocity attained in the stack, the velocity increases from the point of entrance until the maximum is reached. The vertical component of the entrance velocity depends on the rate of flow by volume, the cross-sectional area of the inlet, and the angle of the entrance. This points to the capacity of the fitting as a measure of the "practical capacity of the stack.

We will define the capacity of the fitting as the rate of flow in gallons per minute at which the water just begins to build up in the vertical part of the fitting above the inlet branch of the fitting. With any rate of flow not exceeding this value then the stack, barring stoppage or marked retardation, will not be completely filled at any point.

Hunter is speaking here of the conditions under which water is flowing from the horizontal branch into the stack, but no water is flowing down the stack from a higher level. Continuing with Hunter's discussion:

Determinations were made with different fittings on both 2-and 3-in. stacks as follows: The fittings were set in the top of the stack, and water was introduced at known rates through a trap and the inlet fitting. So long as the water flowed freely with no appreciable retard in the fitting, the rate was considered below that fitting capacity. The rate at which the first tendency to back vertically into the fitting above the level of the inlet appeared, was taken as the fitting eapacity. When the water stood above the level of the inlet, even temporarily during the sustained rate of flow, it was considered that the capacity had been exceeded. This last condition in the case of only one inlet to the stack would do no particular harm, and it should be noted that the rate of flow that causes the water to stand in the fitting is greatly in excess of the rate at which the tendency to build up first appears, double the rate in some cases. The flow was maintained for from 15 to 30 seconds by means of tanks, thus giving ample time for observation and for any effect from the lower portions of the stack to be transmitted. Various lengths of stacks from 30 to $45 \mathrm{ft}$., both with and without house drains were employed, but as no modifying effect from the part of the system below the fitting was observed in any case, only the fitting and tank connections are illustrated in figure 39 , showing a double $Y$ fitting with water introduced simultaneously at both inlets.

The preceding description applies to capacities with entrance at one level with either one or two inlets. For entrance at two levels, two fittings of the kind under test were set at two points in the stack approximately $11 \mathrm{ft}$ apart, and a 1 -in. glass tube bent in $L$ shape was set in a side inlet in the lower of the two fittings and water introduced simultaneously at known rates through the main inlets of the two fittings as before. Any retard or interference in the lower fitting sufficient to cause a slight backflow, neglecting splashes, into the glass $L$ tube was taken as cxceeding the capacity of the fitting under these conditions. As might be expected, the tendency is toward an increase in eapacity with the water introduced at two levels. This is essentially different from the effects in pipes flowing full. It therefore seems safe to assume that the capacity of a given stack with entrance points at more than one level is not less than the capacity of the same stack with entrance points at one level only. In fact, there is very strong evidence that the capacits increases with the increase in number of entrance points at different levels, tending toward a maximum capacity measured by the stack flowing full with the naximum velocity attained by the water flowing in a vertical stack of that diameter. What we liave really determined is therefore, the maximum capacity of the stack for the methods of construction that give a relatively small maximum capacity compared to what might be secured by other methods of design or construction.

From these tests, which were marle only on 2 and 3-in. diameter stacks, Hunter concluded that the stack capacity could be represented approxi. mately by an equation of the type

where

$$
Q=k d^{2}
$$

$Q=$ the permissible volume rate of flow into the stack in gallons per mimute

$d=$ the diameter of the stack in inches

$k=$ an empirical constant.

Hunter gives the values

$$
\begin{aligned}
& k=22.5 \text { for } 45^{\circ} Y \text { inlets } \\
& k=11.25 \text { for sanitary } T \text { inlets. }
\end{aligned}
$$

On the basis of this reasoning and the experimental results with 2 - and 3 -in. stacks, Hunter gave the following table of stack capacities in BH13 [3].

\section{TABLE 3. Carrying capacity of stacks constructed with

\begin{tabular}{|c|c|c|}
\hline \multirow{2}{*}{ Diameter of stack } & \multicolumn{2}{|c|}{$\begin{array}{c}\text { Flow into stack } \\
\text { through- }\end{array}$} \\
\hline & Sanitary T & $45^{\circ} Y$ \\
\hline $\begin{array}{l}\text { in. } \\
2 \text { (experimental data) } \\
3 \text { (experimental data) } \\
4 \text { (extrapolated) } \\
5 \text { (extrapolated) } \\
6 \text { (extrapolated) } \\
8 \text { (extrapolated) }\end{array}$ & $\begin{array}{r}g p m \\
45 \\
100 \\
180 \\
230 \\
405 \\
720\end{array}$ & $\begin{array}{r}g p m \\
90 \\
200 \\
360 \\
560 \\
810 \\
1,440\end{array}$ \\
\hline
\end{tabular} single or double fittings}

Water introduced at one level only. (Hunter)

No tests were made with water introduced through single fittings, and no quantitative test results were reported for the case in which the water is introduced into the stack at more than one level.

An illustration of a case in which the fitting capacity has been exceeded considerably is shown in figure 1. This photograph was taken in the course of the investigation reported here. It shows a 3 -in. double sanitary tee with 3 -in. side inlets made of transparent plastic material with its inside dimensions closely simulating those of the corresponding metal fitting. Flows of $100 \mathrm{gpm}$ are entering the fitting from each horizontal branch, but there is no flow down the stack from higher levels. It will be observed that the water is boiling up in the stack somewhat above the level of the branches. According to Hunter's formula (eq 1, using the value 11.25 for $k$ ), the capacity of the fitting is approximately $100 \mathrm{gpm}$. Thus Hunter's criterion indicates that a flow of $200 \mathrm{gpm}$ 


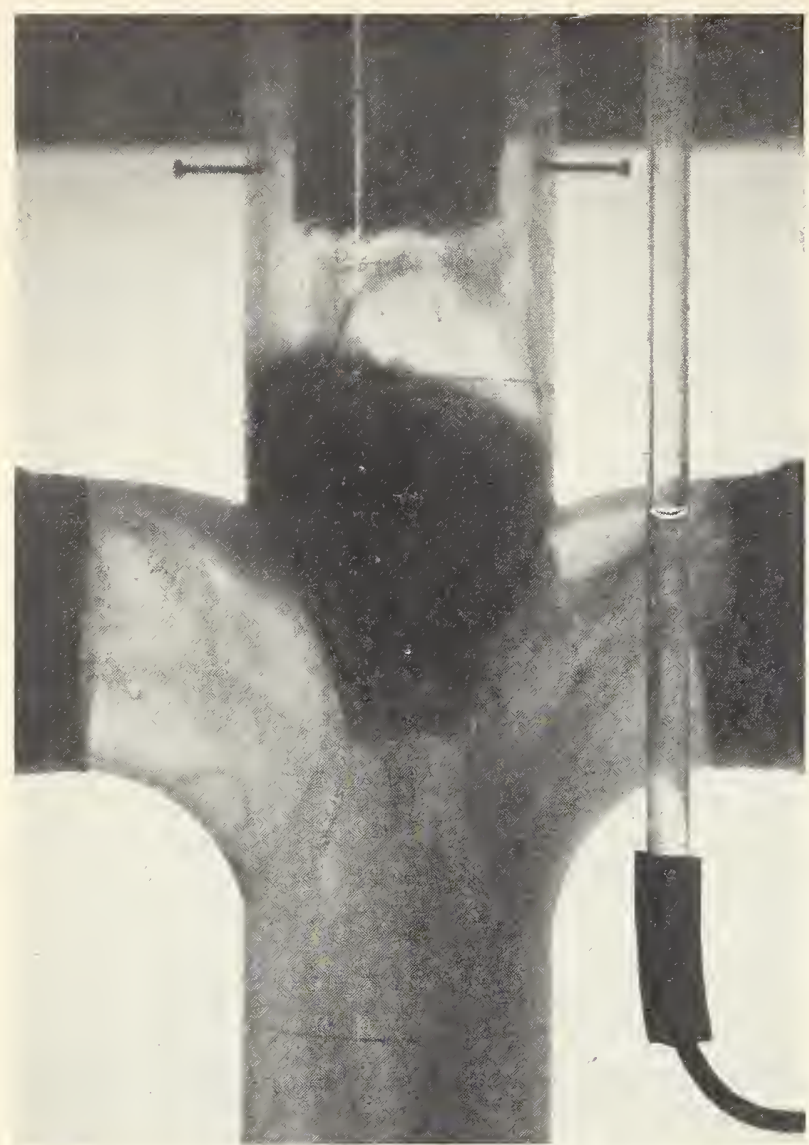

Figure 1. Flow into stack from two horizontal branches at same level, showing case in which the capacity of the fitting is exceeded.

Total flow from branches is 202 gallons per minute. No flow down stack from higher levels.

would overload the fitting, and figure 1 shows that this is actually the case

It will be observed also that the meniscus in the manometer shown in figure 1 is slightly below the top of the horizontal branch, showing that no backplessure in the branch is created by this condition. This manometer is connected into the branch at a distance of 4 branch diameters from the stack, or approximately $1 \mathrm{ft}$.

In BH13 [3] Hunter makes the following further statements:

With a system composed of vertical and horizontal sections of the same diameter throughout, it is evident that on the assumption that no static head may develop, the limit of carrying capacity will first be reached in the horizontal sections of the system. This at once suggests the separate consideration of the horizontal and vertical sections.

Apparently, in view of the varying degrees to which the system or parts of the system may be filled, a very rough approxination of the maximum carrying capacity is all that may be hoped for. The fact that an appreciable head of water developed in any portion of a plumbing system into which branches are discharging tends to impair the efficiency of the dramage indicates a limiting condition on which to base determination of capacities. While the development of a head of water in certain portions of a given system-namely, in unvented small waste branches-may produce no detrimental effects, the assumption of a condition under which no head can develop in any portion of the stack or house drain is certainly a safe procedure and apparently the only one that will permit a general application of results.

Hunter also prepared the stack-loading tables in BMS66 [4]. Unfortunately, however, the data and the reasoning on which these tables were based are no longer a vailable.

\subsection{State University of Iowa}

Dawson and Kalinske have made several contributions to the problem of stack capacities, the most important being reported in Bulletin 10 of the State University of Towa[5]. In this investigation, stacks 3,4 , and 6 in. in diameter and approximately $30 \mathrm{ft}$. high were tested. Various flows were introduced through a horizontal branch near the top of the stack, and pressures and velocities were measured at various points down the stack. The results will be discussed later in this paper. In Technical Bulletin 2 of the National Association of Master Plumbers of the United States[6], they make the following statements bearing on the problem of stack capacities:

Since plumbing stacks cannot be permitted to flow completely full, one important determination is, naturally, how full they can flow without undesirable effects. In other words, what is the carrying capacity of any given size of stack? The maximum allowable rate of flow in a stack, assuming that proper venting exists, will be determined ordinarily by the conditions at the bottom of the stack and in the house drain and sewer. The velocity of water in the building drain and sewer must obviously be considerably less than that in the vertical stack. Therefore, if the building drain and sewer are not to be completely filled, the stack must be considerably less filled, because the ratio of the velocity of the water in the stack and in a horizontal drain laid at a $1 / \mathbf{4}^{-i n c h}$ per foot slope is of the order of 4 to 1 .

Also, a stack which is flowing too nearly full frequently causes considerable noise and vibration. Tests have very definitely shown that too high a rate of flow in a stack produces undesirable noises due to the terrific pneunatic disturbances that are set up. A consideration of the various test data and of different practical items indicates that the stack should not flow over about $1 / 4$ full when the water attains its maximum velocity ....

Dawson and Kalinske give the following table of maximum carrying capacity of stacks:

TABLE 4. Recommended maximum carrying capacity of stacks

[Dawson and Kalinske]

\begin{tabular}{|c|c|}
\hline Diameter oi stack & Maximum flow \\
\hline in. & $g p m$ \\
3 & 90 \\
4 & 180 \\
5 & 350 \\
6 & 560 \\
8 & 1,200 \\
\hline
\end{tabular}


The authors then go on to say:

Another important item that must be determined when the capacity of stacks is under consideration is the amount of water that can enter the stack at any one level. Since the vertical velocity of the water is least at the point of entrance, this part of the stack will be filled up the most. If it becomes filled up too much, however, water will start to head up in the stack, thus retarding the flow from the horizontal drains connected to that level, and also creating undesirable pneumatic effects and considerable noise. Therefore, the allowable rate of flow into the stack at any one floor level must be limited. Our tests and observations have shown that the allowable rate of flow into a stack at any one floor level should not be over one-third of the allowable maximum carrying capacity of the stacks, if the horizontal drains are connected to the stack with sanitary tees and not over one-half of the maximum carrying capacity if $45^{\circ}$ wye connections are used.

Although the procedure followed by Dawson and Kalinske represents probably the most detailed experimental and analytical approacl to the problem that has yet been published, the detailed experimental data reported consisted entirely of those from tests in which all the water was introduced at one level on the stack, rather than at several levels, which will, of course, be the service condition for all buildings greater than one story in height.

\subsection{University of Illinois}

Harold E. Babbitt of the University of Illinois has published the results of stack tests[7], but the most important part of his work related to variations of pressure in the stacks with flow. He gives a discussion of "The useful capacity of 2 -inch, 3-inch, and 4-inch soil stacks", in which he treats the capacity of a soil stack to receive the discharge from plumbing fixtures. Here he cites the results of tests on stacks of the three sizes mentioned above, on which he gives the pressures measured in a horizontal branch $42 \mathrm{ft}$ lower on the stack than the level at which water was introduced in varying amounts. Plotting these results on logarithmic paper, the pressures in the horizontal branch being plotted as ordinates and the rate of discharge down the stacks as abscissas, he shows that these curves for the low flows are straight lines with the slope $5 / 2$, but that the curve to the right for higher flows in the direction of lower powers.

Babbitt assumes that the points at which the curves begin to deviate from the straight lines mark the points at which water can no longer enter the stack freely, and hence that these points represent the capacity of the stack to receive water through the fitting used. The poirts at which these curves begin to deviate fiom straight lines are not clearly markel, and it is asy to differ by as much as 100 percent in reading these points. Neither does the pressure read appear to be a very good criterion for the purpose. Again the results apply only to flow in to the stack at the highest horizontal branch and with the condition that no more water enter's the stack for at least a distance of $42 \mathrm{ft}$ below this point of entry.

\section{Summary of Attempts to Define Stack Capacity}

\subsection{National Bureau of Standards}

Hunter suggested two different criteria. The first is based on the rate of flow entering through two horizontal branches connecting into the stack at the same level and $180^{\circ}$ apart. When the flow has reacherl a value that causes the water to begin to back up in the vertical part of the fitting above the inlet branches he considers that this flow represents the eapacity of the stack.

According to Hunter, eq 1 , with the values of $k$ following it, gives the capacities of stack fittings and hence the practical capacity of stacks. Hunter makes the following important statement:

The fact that an appreciable head of water developed in any portion of a plumbing system into which branches are discharging tends to impair the efficiency of the drainage indieates a limiting condition on which to base determination of capacities . . . the assumption of a condition under which no head can develop in any portion of the stack or house drain is certainly a safe procedure and apparently the only one that will permit a general application of results.

He also states that an upper limit to stack capacity can be set on the basis that when the stack is flowing from one-fourth to one-third full (that is, when the wetted cross section is from one-fourth to one-third of the total cross section of the stack), slugs of water form in the pipe and fall for short distances before they break, and, as these slugs produce large pressure fluctuations in the stack, their formation should be avoided. He does not say whether this criterion refers to the sheet of water flowing down the stack wall when it has reached its maximum or terminal velocity, but it would seem that this must have been his intention. The use of this criterion makes it necessary to consider the problem of flow down the wall of a partially filled vertical pipe, and this will be done in section 5 .

\subsection{State University of Iowa}

Dawson and Kalinske point out the importance of not allowing undesirable pressure conditions to occur in any part of the system. They state that the stack should not flow more than about onefourth full (presumably this refers to the crosssectional area) when the water at tains its maximum velocity. They also suggested that the allowable rate of flow into a stack at any one floor level should not be orer one-third of the allowable maximum carrring capacity of the stack if the horizontal branches are connected to the stack with sanitary tees and not over one-half of the allowable maximum carrying capacity if $45^{\circ} \mathrm{Y}$ connections are used.

\subsection{University of Illinois}

Babbitt's work on stack capacities related mostly to the positive pressures created in the lower part of the stack by water flowing from higher 
lerels. These positive pressures are probably due to two causes. First, it appears obvious that, with a sheet of water flowing down the inside surface of the vertical stack, the $90^{\circ}$ bend at the base of the stack may cause the hollow core in the stack through which air is flowing from the upper part of the stack to become closed off in or just beyond the bend, thus causing an increase in pneumatic pressure as the water flow ing down the stack approaches the bend.

Second, such flows very possibly set up fluctuations of pressure in the lower horizontal branches because of the disturbance of the sheet of water flowing down the wall of the stack as it passes the inlets from the horizontal branches, even when no discharge is taking place from these branches. This type of disturbance has been observed in tests with transparent plastic systems at the National Bureau of Standards. Babbitt makes the following general statement as to stack capacities:

the indications are that a 4 -in. soil stack will take all the water that can be delivered to it in a 5-story building; that a 3 -in. soil stack would take all the water that would be delivered to it in a 3story residence; and that a 2 -in, pipe is unsuitable for use as a soil stack.

\section{The Problem of Stack Capacity}

\subsection{Basic Factors To Be Considered}

The basic factors that have to be considered in connection with the problem of stack capacities are (1) the stack must not flow so full that vibration and undesirable noises will occur, (2) positive pressures that cannot be relieved by venting and which are sufficient to produce sluggish drainage or the flooding of fixtures must not be permitted to occur in any horizontal branch. In the discussions to follow, it will be assumed that the venting system is adequate to relieve partial vacuum conditions within the system, provided that hydrostatic heads in the horizontal branches are not excessive.

\section{a. Noise and Vibration}

Noise and vibration may possibly be caused by the following:

1. Formation and breaking of slugs of water in an overloaded stack. These slugs travel with high velocity and produce large pneumaticpressure fluctuations. Hunter says that these slugs may form if the stack is flowing from onefourth to one-third full. Dawson and Kalinske state that excessive noise and vibration may occur if the stack is flowing more than one-fourth full.

2. It is also possible that these undesirable effects may be due partly to interference with the sheet of water flowing down the stack by the opening or the lower edge of the stack fitting into which a horizontal branch carrying no flow may be

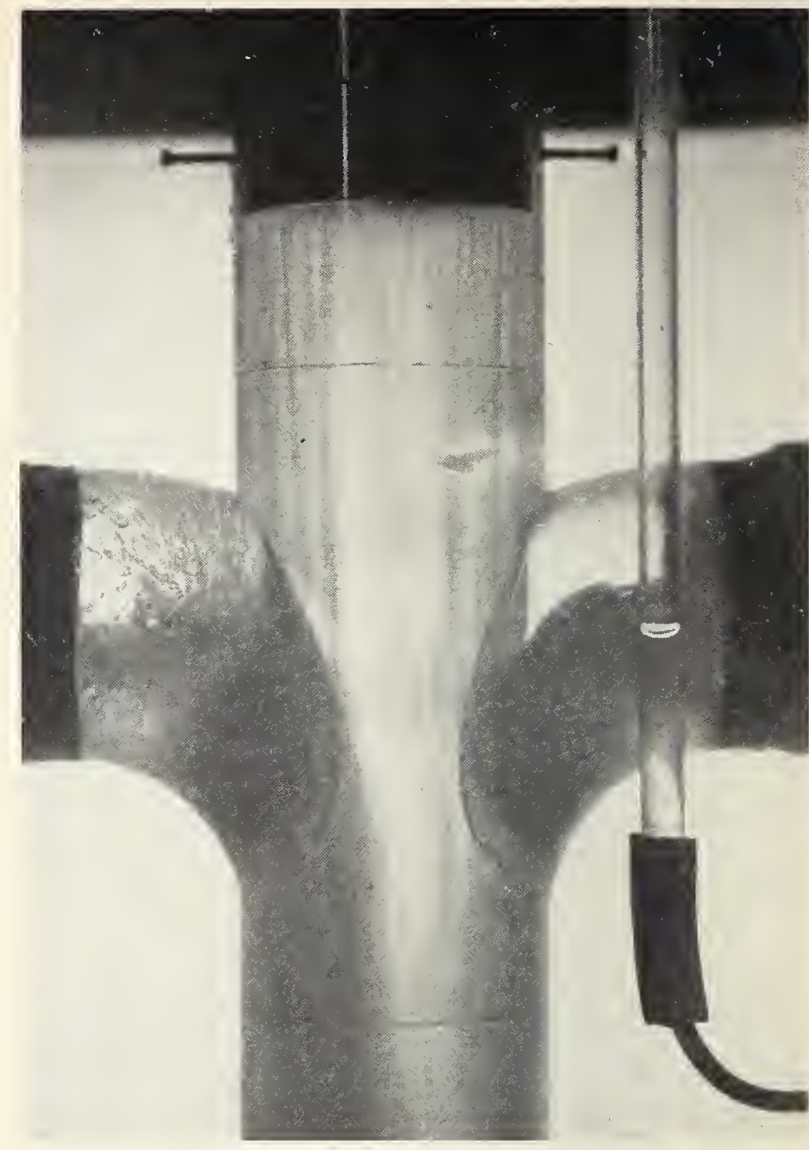

Figure 2. Flow down stack past a sanitary tee, showing deflection of sheet of water toward the center of the cross section and the rollers formed in the branches.

No flow from branches. Flow down stack 124 gallons per minute. Pneu matic pressure in stack is atmospheric.

comnected. This interference has been observed visually in a transparent system in which the sheet of water flowing down the stack passed the side inlets of a double sanitary tee fitting (see fig. 2.) The sheet of water was deflected toward the center of the cross section of the stack by its impact with the bottom of the inlets, and rollers were formed in the inlets of the stack fitting. The pneumatic pressure in the stack was atmospheric.

Figure 3 shows the conditions at the junction of the horizontal branches when there was a slight pressure reduction in the middle of the stack, the conditions of flow being the same as those represented by figure 2. (No flow from branches, $124 \mathrm{gpm}$ down the stack). It will be observed that the rollers are absent when a reduced pressure exists in the stack owing to the tendency for the pressure difference between the branches and the stack to pull the sheet of water inward toward the center of the stack. The deflection of the sheet of water inwardly by the bottom elements of the branches where they intersect the stack is more pronounced than in the former case. 


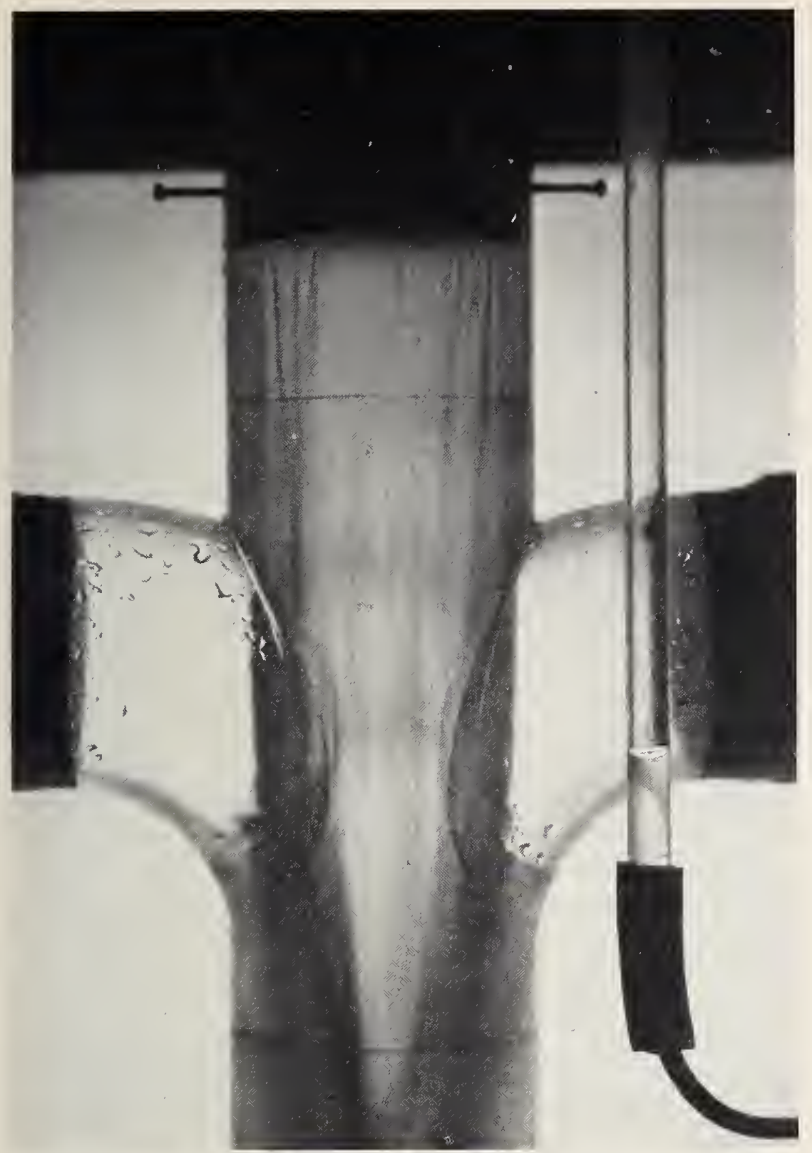

Figure 3. Flow down stack past double sanitary tee, showing deflection of water toward the center of the cross section.

Pneumatic pressure in stack a little less than atmospheric.

3. It is also possible that some disturbance might be caused at the level of a stack fitting through which so much water is discharged into the stack that the cross section of the stack is completely filled at that level.

In summary, it may be stated that in all probability most of the noise and vibration is caused by shugs forming and breaking. The best judgment available at the moment is that, if these undesirable effects are to be prevented, the stack should not be allowed to flow with more than one-fourth of its cross section full when the sheet of water is traveling at its maximum or terminal velocity. This criterion enables us to set an upper limit to the permissible wetted cross section of a stack of any given size, and this can be translated into maximum permissible flows on the basis of information given later in this paper.

\section{b. Excessive pressures in horizontal branches}

1. The question arises as to how much positive hydrostatic pressure is permissible in a branch. The pressure involved may be excessive for the reason that it produces sluggish flow from fixtures on the branch, that it causes fixtures on the branch to be flooded, or that the function of certain vents may be affected adversely. The question of sluggish flow will be ignored for the time lening.

$A$ bathtub, shower stall, or floor drain would be most subject to the effect of this pressure in the horizontal branch as these are the lowest fixtures installed on such hranches. On any horizontal branch to which a number of fixtures are connected, it may be possible to have a flow sufficient to result in the creation of an excessive backpressure in the drain. This may cause the water in the branch to rise through fixture drains into the fixtures not being discharged, such as the bathtub or shower stall, or onto the floor through the floor drain. It will also, under certain conditions, cause sluggish drainage from any of the fixtures mentioned that are discharging.

In addition to the undesirability of sluggish drainage of these fixtures, it is perfectly possible that, where two horizontal branches connect into the stack at the same level through a double sanitary tee fitting, one branch may be flowing under a head sufficient to cause cross flow into the opposite branch, resulting in the creation of a hydrostatic head in the branch not flowing. This could conceivably result in the flooding of the lower fixtures on the branch that is not discharging, although this is mentioned merely as a possibility, not as a probability.

A conclition similar to the one just mentioned could occur when the stack fitting used is a single sanitary tee fitting and little or no flow is coming down the stack from above. In this case, an excessive flow in the branch coukd result in backpressure caused by the stack becoming filled at the branch level. This, of course, represents a condition similar to that used in determining the "practical capacity" of the fitting, on which Hunter based some of his work on stack capacities mentioned in section 3.1 of this paper.

Of course, the two latter conditions are likely to happen only if the load on the horizontal branch is too heavy, but it gives one more reason for limiting the load on horizontal branches.

It is obvious that if a vent pipe connects to a horizontal branch that is flowing under a slight pressure at that point, the vent may be rendered ineffective at that time.

In view of the points considered above, it would seem that the maximum hydrostatic head in the horizontal branch should be limited to an amount that will just fill the branch near its junction with the stack, at least in long horizontal branches to which a number of fixtures are connected.

The factors that tend to produce excessive pressures in lorizontal branches include the following: (a) pneumatic pressures in the stack, (b) excessive rates of flow in the branch, (c) interference with flow from the branch by flow down the stack coming from higher levels, and (d) obstructions in the branch or stack.

The pressure existing at any level in the stack is transmitted through the sheet of water flowing 
down the wall of the stack to the horizontal branch, and, if the drain is filled with water at or near its outlet, exerts a backpressure on the branch. This is a complicated problem, and, as far as the authors know, has never been analyzed. It will be treated later in this paper.

The question of obstructions in the stack or branch will be ignored, as the existence of such obstructions constitutes an abnormality that will rarely, and should never, occur.

The other factors listed-excessive rates of flow in the branch and the interference of flows-must be considered together, assuming that the branch is not so overloaded that an excessive head will be built up even when no water is flowing down the stack from higher levels. The principal cause of hydrodynamic backpressure on the branch is the interference of the sheet of water flowing down the stack with the flow from the branch. The physics of this phenomenon will be explained more fully later in this paper, but the cause of this backpressure will be pointed out here

The sheet of water flowing down the wall of the stack at high velocity has considerable momentum. In order that the water may flow out of the branch, it is necessary that it deflect the sheet of water flowing down the wall past the branch inlet to the stack. But, by a well-known law of physics the deflection of the shect, with its consequent change in momentum, can be produced only by means of a force exerted on it to produce the deflection, and this force is supplied through the pressure in the stream from the branch. The greater the the momentum of the flow down the stack, the greater will be the backpressure required to permit a given flow from the branch. Also, for a given rate and velocity of flow down the stack, the greater the flow from the branch, the greater will be the pressure required in the branch. Consequently, assuming the pneumatic pressure in the stack to be the same at all levels for simplicity, it is obvious that horizontal drains at the higher floors of a multistory building can be loaded more heavily than can the lower branches as less water will be passing the outlets of the higher branches than the lower ones, and hence there will be less back-pressure caused for a given flow from a branch at a high level than one having the same rate of outflow at a lower level. This fact, as far as the authors know, has never been pointed out in the literature, and ret it has an important bearing on the design of building drainage systems.

\subsection{Tentative Definition of Stack Capacity}

From what has been said, it is obvious that we cannot speak of the capacity of a stack without considering the distribution of load vertically on the stack. Hence the capacity of a stack will vary, depending on the vertical load distribution, and our definition must take account of this fact. It also seems from the preceding discussion that any definition of stack capacity nust be based on the question of pressures in the horizontal branches. Even though it is fully realized that the development of a small head in the branches may not necessarily be a serious objection, nevertheless, consideration of the hydrodynamic pressures in the branches oflers a necessary and possibly sufficient condition on which to base the definition. 'The following definition of stack capacity is offered, therefore, as a tentative definition, with the full realization that later and more detailed investigation may require that it be changed. It is believed that, if the branch pressures are kept down to reasonable values, there will be no noise or objectionable vibration, but this matter is open to further investigation.

The capacity of a drainage stack at the level of any horizontal branch is defined as the total flow at that level which causes a preassigned positive pressure in the horizontal branch which cannot be relieved by venting or, in the case of horizontal branches low on the stack, by increasing the size of the building drain.

Several comments are required to clarify the above definition. First, by total flow we mean the sum of the flows from the horizontal branch in question and from fixtures higher up on the system. 'This total flow may be divided in any way between the branch and the part of the stack imimediately above the branch.

Second, as it is specified that the preassigned positive pressure cannot be relieved by venting, this means that it must be a hydrostatic pressure due to a head of water. Were it a pneumatic pressure, it could be relieved by venting.

Third, as it is specified that the preassigned positive pressure cannot be relieved in some instances by increasing the size of the building drain, this means that the size of the building drain is adequate. Otherwise, for horizontal branches on the lower part of the stack, the hydrostatic pressure under consideration could be relieved, at least partially, by increasing the diameter of the building drain.

Fourth, if we require that this preassigned positive pressure shall never be exceeded, this will lead to oversizing the pipes. Rather, we mean that it shall probably not be exceeded more than a certain specified portion of the time during which the fixtures on the system are being used with their maxmum assumed frequency, as during the morning rush hours in a hotel. "For a discussion of this question of maximum frequencies, see [12].

\subsection{Terminal Velocity and Terminal Length}

In any adequate study of stack capacities, we must have information as to the terminal velocities and terminal lengths of fall of the sheet of water in the stack.

By terminal velocity we mean the maximum velocity of fall attained by the water column in the pipe, whether the cross section of the pipe is filled or whether the water is flowing in a sheet down the wall, when the water is allowed to fall from a given 
level under the force of gravity and is retarded by the wall friction through a long enough distance to attain this velocity. When these two forces balance, the water is no longer accelerated, so that the velocity from this point down is constant.

$\mathrm{B} y$ terminal length we mean the distance through which the water must fall before it attains the terminal velocity. Theoretically, the water would have to fall an infinite distance before this condition would exist, but, for all practical purposes, a finite limit can be established.

\section{Terminal Velocities in Stacks}

\subsection{Tests at the National Bureau of Standards}

Hunter [8] made tests on the fall of water columns in vertical stacks up to $100 \mathrm{ft}$ in height built of 1-, 2-, and 3-in. galvanized steel pipe. His experimental procedure was as follows: Gage holes were tapped in the vertical stack at intervals of $10 \mathrm{ft}$ in height. A quick-opening valve was installed at the bottom of the stack. With the valve closed, the pipe was filled with water to the level of the first gage hole. The valve was then opened quickly, and the time required for the water to flow out of the pipe was observed. This process was repeated, the pipe being filled to the height of each gage hole successively. To obtain the terminal velocity for each diameter of pipe, he plotted the lengths of the falling column as ordinates and the times of descent as abscissas. This gave a straight line in the region where the water was falling at terminal velocity, and the slope of this line gave the terminal velocity.

In order to establish limits within which the measured terminal velocities should lie, Hunter computed terminal velocities for smooth and for very rough pipe over a range of diameters of from 1 to 8 in. These curves, together with the experimentally determined velocities, are shown in figure 4 . The three experimental points lie between the two curves, as they should, and they are closer to the curve for smooth pipe than the curve for very rough pipe, as would be expected. Because of this good agreement of the experimental values with the values given by the smooth-pipe curve, Hunter concluded that the smooth-pipe curve given in figure 4 might be used to set the upper limit of terminal velocities for flow out of plumbing stacks completely filled with water. Table 5 gives these velocities.

TABLE 5. Terminal velocities in vertical pipes flowing full.

\begin{tabular}{|c|c|c|}
\hline \multicolumn{2}{|c|}{ Diameter of pipe } & \multirow{2}{*}{ Terminal ve- } \\
locity
\end{tabular}

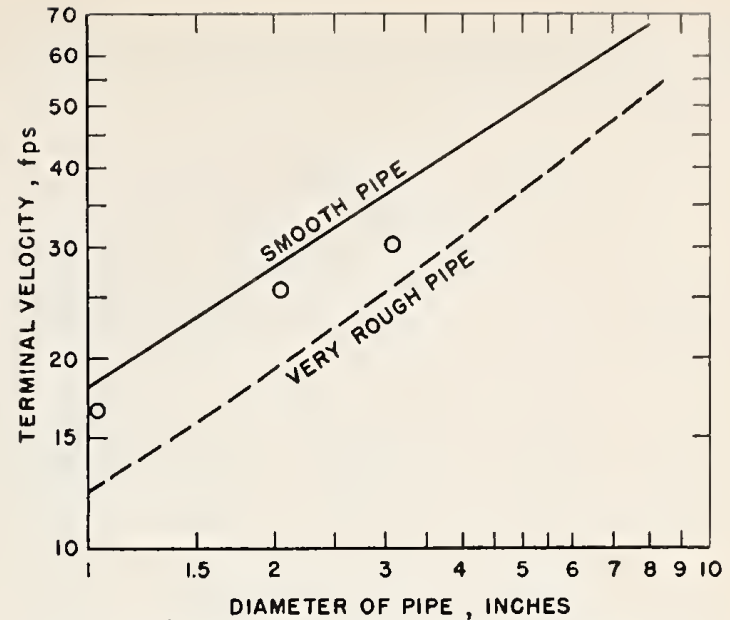

Figure 4. Terminal velocities for flow in vertical pipes flowing full under the force of gravitation.

Hunter [2] also conducted tests on terminal velocities in 2- and 3 -in. cast-iron stacks flowing partly full. He used a 3-in. stack $45 \mathrm{ft}$ in height, open top and bottom, and introduced the water through a $45^{\circ}$ double $Y$ fitting at the top of the stack. The velocities were measured with a pitot tube at the bottom of the stack. Various heights of fall from 5 to $45 \mathrm{ft}$ were used. From these tests he found the terminal velocity of flow in the 3 -in. stack to be about $16.8 \mathrm{fps}$, attained in a height of about $15 \mathrm{ft}$, for a flow of $100 \mathrm{gpm}$; and $32.4 \mathrm{fps}$, attained in a height of about $75 \mathrm{ft}$ for a flow of $200 \mathrm{gpm}$.

He also made tests on a 2 -in. stack, obtaining the following results: for a flow of $45 \mathrm{gpm}$, a terminal velocity of $18.5 \mathrm{fps}$, attained in a fall of about $20 \mathrm{ft}$; and for a flow of $90 \mathrm{gpm}$, a terminal velocity of $24 \mathrm{fps}$, attained in a fall of about $20 \mathrm{ft}$.

Hunter remarks that, with flows of $90 \mathrm{gpm}$ in the 2-in. stack and $200 \mathrm{gpm}$ in the 3 -in. stack, slugs of water completely filling a short length of the pipe occasionally formed, and the maximum velocity of these slugs approached the maximum velocity for a completely filled stack.

\subsection{Tests at the State University of Iowa}

Dawson and Kalinske conducted experiments on flow in partly filled rertical pipes in order to determine terminal velocities for different conditions [5]. They tested 3-, 4-, and 6-in. installations with the water entering the stacks through a single stack fitting at the top. They do not state of what material the stacks were made or what the building drain lengths were. The stacks were provided with vent pipes at two levels and discharged through a $90^{\circ}$ bend into a short horizontal drain. However, it is not known whether the vents were open or closed while taking velocity measurements. The height of the stacks was about $30 \mathrm{ft}$ in all cases. Using a pitot tube, they measured the average velocities correspond- 
ing to different heights of fall and rates of flow. Table 6 gives the values of the terminal velocities which they obtained.

TABLE 6. Terminal velocities of flow in vertical pipes flowing partly full

(Dawson and Kalinske)

\begin{tabular}{|c|c|c|c|c|}
\hline $\begin{array}{l}\text { Diameter } \\
\text { of stack }\end{array}$ & Flow & Flow & $\begin{array}{l}\text { Terminal } \\
\text { velocity }\end{array}$ & $\begin{array}{l}\text { Thickness } \\
\text { of sheet } \\
\text { (computed) }\end{array}$ \\
\hline $\begin{array}{r}i n . \\
3 \\
3 \\
3 \\
3\end{array}$ & $\begin{array}{r}g p m \\
45 \\
90 \\
135 \\
180\end{array}$ & $\begin{array}{c}c f s \\
0.1003 \\
.2005 \\
.3008 \\
.4010\end{array}$ & $\begin{array}{l}f p s \\
11.5 \\
15.4 \\
17.6 \\
19.5\end{array}$ & $\begin{array}{l}\text { in. } \\
0.135 \\
.215 \\
.290 \\
.355\end{array}$ \\
\hline $\begin{array}{l}4 \\
4 \\
4 \\
4 \\
4\end{array}$ & $\begin{array}{r}90 \\
135 \\
190 \\
240 \\
300\end{array}$ & $\begin{array}{l}.2005 \\
.3008 \\
.4235 \\
.5345 \\
.6684\end{array}$ & $\begin{array}{l}16.8 \\
19.0 \\
20.4 \\
21.2 \\
22.0\end{array}$ & $\begin{array}{l}.139 \\
.185 \\
.250 \\
.315 \\
.385\end{array}$ \\
\hline $\begin{array}{l}6 \\
6 \\
6 \\
6 \\
6 \\
6 \\
6\end{array}$ & $\begin{array}{l}115 \\
165 \\
220 \\
345 \\
450 \\
560 \\
675\end{array}$ & $\begin{array}{r}.256 \\
.367 \\
.490 \\
.754 \\
1.003 \\
1.248 \\
1.505\end{array}$ & $\begin{array}{l}12.3 \\
14.4 \\
17.4 \\
21.7 \\
25.0 \\
26.5 \\
27.5\end{array}$ & $\begin{array}{r}.160 \\
.200 \\
.220 \\
.275 \\
.320 \\
.380 \\
.445\end{array}$ \\
\hline
\end{tabular}

From the terminal velocities given in the table, the cross-sectional areas, $a_{1}$, of the sheets of water were computed from the known values of the flows. The thickness, $T$, of the sheet in each case was then computed from the equation

$$
a_{1}=\pi\left(d_{1}-T\right) T,
$$

in which $d_{1}$ is the diameter of the stack, and the values thus obtained are also given in the table.

The same computations were made from Hunter's data, and the results are given in table 7 .

TABLE 7. Terminal velocities of flow in vcrtical pipes flowing partly full

(Hunter)

\begin{tabular}{|c|c|c|c|c|}
\hline $\begin{array}{c}\text { Diameter of } \\
\text { stack }\end{array}$ & Flow & Flow & $\begin{array}{c}\text { Terminal } \\
\text { velocity }\end{array}$ & $\begin{array}{c}\text { Thickness of } \\
\text { shcet com- } \\
\text { puted }\end{array}$ \\
\cline { 1 - 1 } \cline { 1 - 2 } in. & $g p m$ & $c f s$ & $f p s$ & in. \\
3 & 100 & 0.2225 & 16.8 & 0.223 \\
3 & 200 & .450 & 32.4 & .235 \\
2 & 45 & .1003 & 18.5 & .130 \\
2 & 90 & .2005 & 24.0 & .220 \\
\hline
\end{tabular}

A tentative plot was made of these data with terminal velocities plotted against thickness of the sheet of water, but the results were rather disappointing. For each diameter of stack, there is a steady increase in terminal velocity as the thickness of the sheet increases, and the data for different diameters of stack yield separate curves, but the curves do not fall in order of increasing diameters. Hunter's observation for the 3-in. stack with a flow $100 \mathrm{gpm}$ agrees well with Dawson and Kalinske's observation for the 3-in. stack, but Hunter's observation for the 3 -in. stack with a flow of $200 \mathrm{gpm}$ lies far above the terminal velocities

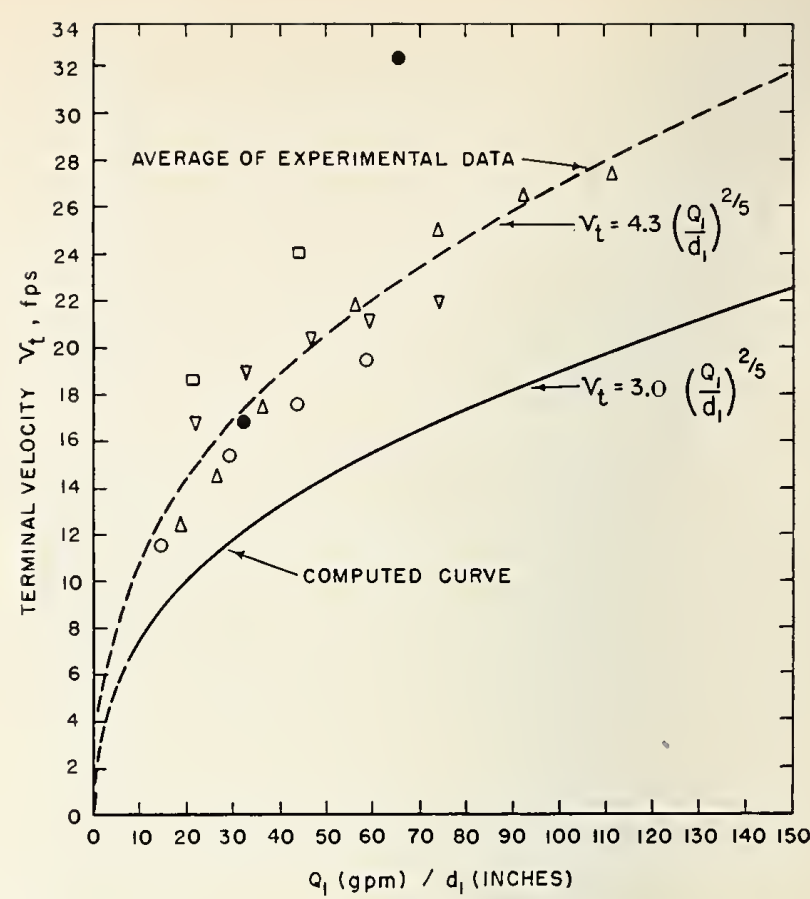

Figure 5. Terminal velocities for flow in partially filled vertical pipes.

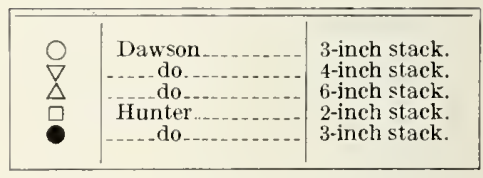

obtained in any of the other tests. It was observed in connection with the last two measurements mentioned that the thickness of the sheet is nearly the same in the two cases, although the flow is double in one case what it is in the other. This fact throws doubt on these two measurements. The data given in tables 6 and 7 are plotted in figure 5 .

Dawson and Kalinske [5] developed equations for terminal velocity, starting with the equation

$$
m a=m g-k \pi d_{1}(\Delta L) w v^{2}
$$

where

$m=$ the mass of water $=(\Delta L) A w / g$

$a=$ the acceleration of the water at any point

$g=$ the acceleration of gravity

$\dot{d}_{1}=$ the diameter of the stack

$v=$ the average velocity of the water at any cross section

$\Delta L=$ the length of the slug of water under consideration

$A=$ the cross-sectional area of the slug of water $w=$ the specific weight of the water

$k=$ a dimensional constant.

Although their expression for the fricition term involves a dimensional constant, whereas the con- 
stant could have been made dimensionless by writing the density, $\rho$, of the water in plaee of the speeific weight, $w$, their resulting expressions for terminal velocity and terminal length appear to be correctly derived under the simplifying assumptions made.

Dawson and Kalinske derive the following expression for terminal velocity, which is expressed here in the notation of the present paper for simplicity of comparison:

$$
v_{t}=\left(Q_{1} g / \pi k d_{1}\right)^{1 / 3}
$$

\subsection{Derivation of Equation for Terminal Velocities}

The following derivation of the equation for terminal veloeities is an approximate one. In it the sheet of water is treated as if it were a rigid body instead of a fluid sheet with a radial velocity gradient. The more accurate solution would involve a computation of the turbulent boundary layer down the pipe, but, in view of the extremely complicated equations that would be involved, this would not be warranted in connection with our present problem.

We consider the sheet of water as if it were a rigid body moving down a plane vertical wall, acted on by the oppositely directed forces of gravitation and friction. We assume that the sheet starts with an initial vertically directed velocity downward having the magnitude $v_{0}$, where $v_{0}$ is less than the terminal velocity, $v_{t}$, which the sheet will attain ultimately if the length of fall is great enough. This is a further simplification as the water actually flows down the interior surface of a pipe. As the velocity of fall inereases with $z$, where $z$ denotes the distance measured down the stack from the point of entry, the thickness of the sheet decreases with $z$, becoming constant when $z$ attains the value of $z_{t}$, the terminal length. Other symbols that will be required are:

$d_{l}=$ the diameter of the stack

$Q_{1}=$ the volume rate of flow down the wall

$v=$ the velocity of fall corresponding to any given distanee of fall, $z$

$\rho=$ the density of the water

$g=$ the aceeleration of gravity

$\Delta L=$ the length of an elementary volume of water

$T=$ the thickness of the sheet eorresponding $t=$ time to any given value of $v$

$\lambda=\mathrm{a}$ dimensionless constant

We start with the fact that the accelerating force is equal to the gravitational foree less the frictional resistance.

$$
m \frac{d v}{d t}=m g-\tau_{0} \pi d_{1} \Delta L,
$$

where $\tau_{0}$ is the wall shear per unit area, and the elementary volume of water is assumed to be $\pi d_{1}$ units wide. But

so

$$
m=\rho Q_{1} \Delta t
$$

$$
\rho Q_{1} \frac{d v}{d t} \Delta t=\rho Q_{1} g \Delta t-\tau_{0} \pi d_{1} \Delta L
$$

We now define $\tau_{0}$ by the relation,

$$
\tau_{0}=\frac{\lambda \rho}{2} v^{2}
$$

and replace $\Delta L$ by its value, $v \Delta t$. Equation 5 then becomes

$$
\rho Q_{1} \frac{d v}{d t} \Delta t=\rho Q_{1} G \Delta t-\frac{\pi \lambda \rho}{2} d_{1} v^{3} \Delta t
$$

or

$$
\frac{d v}{d t}=g-\frac{\pi \lambda}{2 \bar{Q}_{1}} d_{1} v^{3}
$$

We now obtain the expression for the terminal velocity, $v_{t}$, by placing $d v / d t$ equal to zero:

$$
v_{t}=\left(\frac{2}{\pi} \frac{g Q_{1}}{\lambda d_{1}}\right)^{1 / 3} .
$$

It can be shown easily that $\lambda$ is equal to $f / 4$, where $f$ is the dimensionless friction coefficient in the Darcy-Weisbach formula for pipe flow. It is a function of the Reynolds number, $R_{e}=T v / \nu$, approximately, and of the roughness ratio, $k_{s} / R$ or $k_{s} / T$, where $\nu$ is the kinematic viscosity of water, and $k_{s}$ is the average height of a roughness element.

The above expression for the terminal velocity contains the frietion coeffieient $\lambda$, and it will be convenient to modify the expression to eliminate this. To do this we use the following equation given by Keulegan for flow in open channels, the equation being based on the Manning formula [9]:

$$
\frac{\bar{v}}{v_{*}}=8.12\left(\frac{R}{k_{s}}\right)^{1 / 6},
$$

where $\bar{v}$ is the mean velocity in the cross section, $R$ is the hydraulic radius, and $v_{*}$ is the shear velocity, defined by the relation,

$$
v_{*}=\sqrt{\tau_{0} / \rho}
$$

and $k_{s}$ is the sand roughness, which may be looked on as representing the distances that the sand grains would projeet from a surface having the same frictional resistance as the surface being considered.

We note that the $\bar{v}$ in eq 9 is the same as the $v$ in the other equations, and we eliminate $\tau_{0}$ between eq 6 and 9 , and then $v_{*}$ between eq 9 and 10 , obtaining finally

$$
\lambda=0.0303\left(\frac{k_{s}}{T}\right)^{1 / 3},
$$


if we replace $R$ by $T$, as we can do approximately. Substituting this value of $\lambda$ in eq 8 , we have

$$
v_{t}=\sqrt[3]{21 g \frac{Q_{1}}{d_{1}}\left(\frac{T_{t}}{k_{s}}\right)^{1 / 3}}
$$

$T_{t}$ being written for $T$ to indicate that the value of $T$ is that corresponding to the terminal velocity.

One further change will be made in the expression for terminal velocity by eliminating the thickness $T_{t}$ of the sheet of water by means of the relation between the thickness of the sheet, the cross-sectional area of the sheet, and the rate of flow. This relation is given by the approximate expression

$$
Q_{1}=\pi d_{1} T_{\imath} v_{\imath}
$$

or by the more accurate expression

$$
Q_{1}=\pi\left(d_{1}-T_{t}\right) T_{t} v_{t}
$$

If we use the approximate expression in eq 13 , there results:

$$
v_{t}=\sqrt[3]{21 g \frac{Q_{1}}{d_{1}}\left(\frac{Q_{1}}{\pi d_{1} v_{t} k_{s}}\right)^{1 / 3}},
$$

or

$$
v_{\imath}=2.22\left(\frac{g^{3}}{k_{s}}\right)^{1 / 10}\left(\frac{Q_{1}}{d_{1}}\right)^{2 / 5}
$$

The phenomena of flow down a vertical stack is independent of the Reynolds number for two reasons. First, because of the fact that the water is falling rapidly under the influence of gravitation, the velocity is nowhere small enough, except possibly for an extremely short distance at the point of entrance, for the fluid friction to play an important part. Second, as the Reynolds number for the flow can be written as $T v / \nu$, and by the approximate equation, eq 13 , we see that for a given flow, $T$ is inversely proportional to $v$, then the Reynolds number for the given flow down the stack will be constant as long as there are no additions to the flow as it passes down the stack. Thus the flow phenomena can be considered a function of the relative roughness, but the Reynolds number can be neglected.

An appropriate value of $k_{s}$ has been determined from data on friction losses for flow through new cast-iron soil pipe tested by Hunter [10] and yields the approximate value, $k_{s}=0.00083 \mathrm{ft}$. (See Appendix I for the derivation of this value.) Rouse [11] gives the value, $k_{s}=0.00085 \mathrm{ft}$ for new cast-iron pipe, so the agreement is good.

We can express eq 12 in more convenient form for computation. We replace $T_{t}$ by its approximate value from eq 13 , take the value of $k_{s}$ as $0.00083 \mathrm{ft}$, and reduce the resulting equation, obtaining (for cast-iron soil pipe)

$$
v_{t}=12.80\left(\frac{Q_{1}}{d_{1}}\right)^{2 / 5},
$$

where $v_{\imath}$ is expressed in feet per second, $Q_{1}$ is in cubic feet per second, and $d_{1}$ is in feet.

If we wish to express $\beta_{1}$ in gallons per minute and $d_{1}$ in inches, we write (for cast-iron soil pipe) eq $16 \mathrm{a}$ as

$$
v_{t}=3.0\left(\frac{Q_{1}}{d_{1}}\right)^{2 / 5} .
$$

Equation $16 \mathrm{~b}$ is plotted in figure 5, together with the experimental data obtained by Hunter and by Dawson and Kalinske. An average curve having the equation

$$
v_{\imath}=4.3\left(\frac{Q_{1}}{d_{1}}\right)^{2 / 5}
$$

is drawn through the experimental points.

As would be expected, the experimental points scatter considerably, for the terminal velocity is a quantity that is very difficult to measure. The fact that stands out strikingly is that all the measurements of the experimenter's referred to above lie above the curve that has been established from resistance measurements on cast-iron soil pipe. There are certain reasons why this tendency might exist, the most probable one relating to the velocity distribution in the sheet of water. A very steep velocity gradient exists in the sheet of water, increasing from zero at the wall to a maximum at the inner surface of the sheet. The experimenters made their observations with a pitot tube with its dynamic opening pointing vertically upward through the vertical sheet of water. It was impossible to get the pitot tube close to the wall where the lowest velocities existed, and hence, in averaging their nreasured velocities, they may not have taken into account adequately the lower velocities near the wall.

A conversation with Professor Dawson bore out the above supposition. He stated that his measurements were made in the outer layers of the sheet and hence did not represent a true average of the velocities in the sheet. The difficulties involved in measuring the true terminal velocity are very great, and too great accuracy must not be expected.

One other point should be mentioned here. Experiments made by one of the authors since the earlier work reported in this paper have shown that there is considerable variation in air content radially in the sheet of water. At the wall the sheet is made up entirely of water. As we pass inward toward the water surface in the pipe, the air content in the sheet increases, until near its inner edge it is roughly 50 percent air by volume. This would have a considerable effect on pitot tube readings made in the sheet, but the tendency would be to decrease the measured vertical velocities because of the reduction in the effective density of the mixture.

It seems probable that the computed curve expressed by eq $16 \mathrm{~b}$ is more reliable than are the 
measurements of terminal velocity. Further cvidence of this was obtained by one of the author's in a series of careful measurements of terminal velocity. With the above understanding of the conditions in the sheet of water, he was able to get measurements approximating the computed curve in figure 5.

\section{Terminal Lengths in Stacks}

To derive the equation for terminal lengths in sheet flow down the walls of vertical stacks, we return to eq 7 , make the necessary transformations, and intcgrate the rcsult to obtain the expression for the terminal length. We first note that

$$
\frac{d v}{d t}=\frac{d v}{d z} \frac{d z}{d t}=v \frac{d v}{d z}
$$

Making this substitution in eq 7 and solving for $d z$, we have

$$
d z=\frac{1}{g} \frac{v d v}{1-\frac{\pi}{2} \frac{\lambda}{g} \frac{d_{1}}{Q_{1}} v^{3}},
$$

and assuming that $\lambda$ is not a function of $v$, we have from eq 8

$$
d z=\frac{v_{t}^{2}}{g} \frac{\left(v / v_{t}\right) d\left(v / v_{t}\right)}{1-\left(v / v_{t}\right)^{3}}=\frac{v_{t}^{2}}{g} \frac{\theta d \theta}{1-\theta^{3}}
$$

where $\theta=v / v_{t}$.

We can integrate eq 20 directly, obtaining

$$
\begin{aligned}
L_{t}=z \mid \frac{z_{t}}{0}=\frac{1}{3} \frac{v_{t}^{2}}{g}\left[\frac{1}{2} \log _{e} \frac{1+\frac{v}{v_{t}}-\left(\frac{v}{v_{t}}\right)^{2}}{\left(\frac{v}{v_{t}}-1\right)^{2}}-\right. \\
\left.\tan ^{-1}\left(2 \frac{v}{v_{t}}+1\right)\right|_{0} ^{1}
\end{aligned}
$$

We note that if we substitute the upper limit, $v / v_{t}=1$, we obtain an infinite result as the denominator of the first term in the parenthesis becomes zero. We avoid this difficulty by assuming that, when the velocity has reached a value equal to 0.99 times the true terminal velocity, the terminal length has been attained for all practical purposes. Making this substitution for $v / v_{t}$ in eq 21, and inserting the limits, we obtain

$$
\begin{array}{r}
L_{t}=\frac{v_{t}^{2}}{3 g}\left[\frac{1}{2} \log _{e} 29,700-\tan ^{-1} 2.98-\frac{1}{2} \log _{e} 1+\right. \\
\left.\tan ^{-1} 1\right],
\end{array}
$$

or

$$
L_{t}=0.052 v_{t}^{2} \text {. }
$$

We can determine the variation in thickness of the shect of water as it flows down the wall for any rate of flow, diametcr of stack, cntrance velocity, and height of fall by integrating eq 20 for values of $v$ ranging from zcro to $v t$. Practically, it is easier and sufficiently accurate to integrate the equation graphically. 'To do this, we write

$$
\frac{g}{v_{t}^{2}} \int d z=\int \frac{\theta d \theta}{1-\theta^{3}}
$$

where $\theta$ represents the ratio $v / v_{t}$, and we plot values of $\theta /\left(1-\theta^{3}\right)$ against $\theta$ over the range, $\theta=0$ to $\theta=1$. By measuring the areas under the curve from $\theta=0$ to any other desired value, we obtain the corresponding values of

$$
\int \frac{\theta+d \theta}{1-\theta^{3}} \text {, which is equal to } \frac{g}{v_{t}^{2}} \int d z \text {, }
$$

and by multiplying these values by $v_{t}^{2} / g$, we obtain the distance through which the water had to fall to acquire this mean velocity, $v$.

However, our principal interest is to obtain a knowledge of how far a sheet of water must fall before it attains a velocity appreciably equal to the terminal velocity. This can be computed from eq 21 , placing $v$ equal to $0.99 v_{\imath}$, or it can be read from figure 6 , which is a plot of eq 22 for a new cast-iron stack. The necessity of having a knowledge of terminal lengths will appear later in this paper when a method of computing backpressures on horizontal branches at inter-

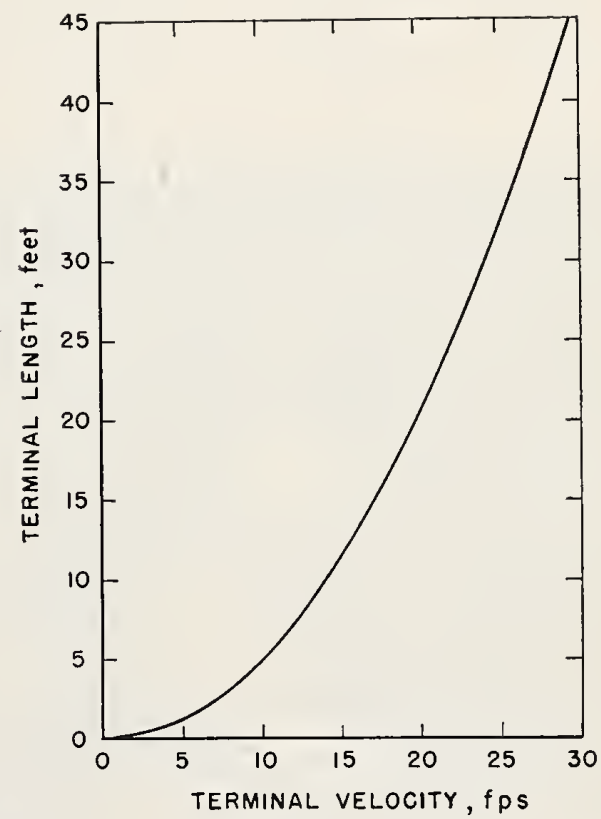

Figure 6. Terminal lengths for flow in partially filled vertical pipes.

Computed from the equation $L_{t}=0.052 t^{\prime}$. 
mediate floor levels will be given. Our knowledge of terminal lengths indicates that in practically all cases the sheet of water in falling through the height of one story, or a little more, attains practically its terminal velocity, which simplifies the application of the theory presented. Consequently, the exact value of the numerical coefficient in eq 22 is not of great importance, and the equation will be used only to give approximate values of the terminal lengths.

If we compare eq 22 with the equation of free fall under the influence of gravity, we find that the sheet of water in the pipe must fall approximately three times as far to attain a given velocity of fall as a body falling freely under the influence of gravity.

\section{Tests on Stacks and Drains}

\subsection{Nature of the Tests}

Because the suggested definition of stack capacity in section 4.2 is based on hydrostatic pressures in the horizontal branches caused by conditions in the stack, it appeared advisable to study first the conditions existing at the junction of one or two horizontal branches connecting into the stack at a given level with water flowing down the stack from ligher floors. It was planned to try to relate the conditions of flow in the stack with the flow conditions in the drain, pressures in the stack, and pressures in the drain. For this purpose a 3 -in. stack and drains of $1 \frac{1 / 2}{2}$, 2-, and 3-in. diameter were selected for the first tests. Double sanitary tee stack fittings were used in the first phase of the investigation. Drawings of these fittings are shown in figures 7,8 , and 9 .

In order to clarify the terms applied to the drainage fittings used at the junction of the stack and the horizontal branches, a word of explanation is in order. The sanitary tee fittings shown in figures 7,8 , and 9 are also known as short-turn T-Y and $90^{\circ}$ short $Y$-branch fittings. A sanitary wye fitting is also known as a long-turn T-Y or a $90^{\circ}$ long $\mathrm{Y}$-branch fitting, and if the fitting is a caulked soil-pipe fitting, it may be known as a combination $Y$ and $1 / 8$ bend.

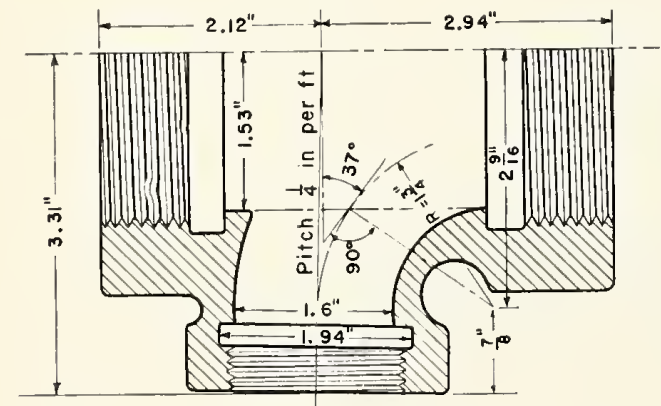

Figure 7. Drainage fittings used in stack tests. $3 \times 3 \times 1 \frac{1}{2} \times 1 \frac{1}{2}$-iuch double sanitary tee.

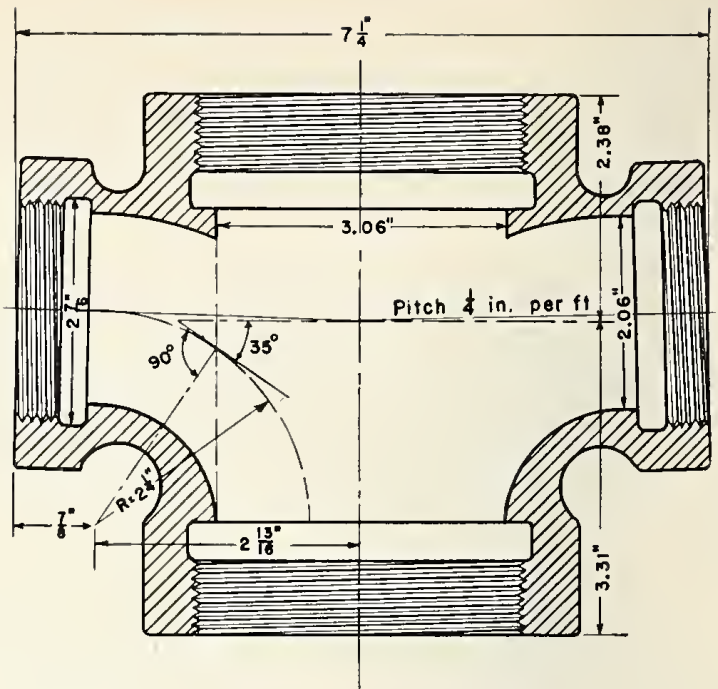

Figure 8. Drainage fittings used in stack tests. $3 \times 3 \times 2 \times 2$-inch double sanitaly tee.

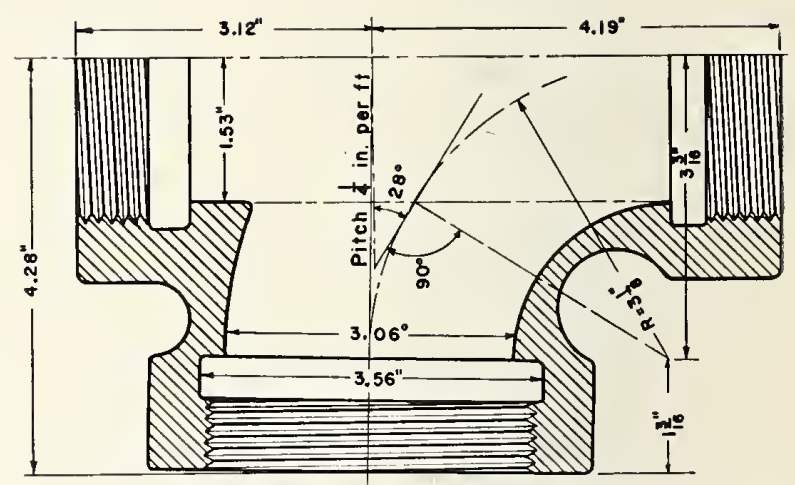

Figure 9. Drainage fittings used in stack tests. $3 \times 3 \times 3 \times 3$-inch double sanitary tee.

\subsection{Simplified Setup for Simulating Con- ditions at the Junction of One or 'Two Horizontal Branches and a Vertical Stack}

In planning the tests the idea was conceived of eliminating a ligh stack and attaining a higher degree of accuracy for the first tests by substituting the equipment shown in figures 10, 11, and 12 . Figure 12 shows the equipment with a transparent-plastic stack fitting and stack substituted for the conventional metal fitting and stack to permit the visual observation of the flow conditions. 'The test results, however, are based entirely on the results obtained with the usual metal stack and fittings.

In the equipment described, the sheet of water flowing down the stack is produced at the level of the stack fitting by installing a second piece of pipe smaller in diameter than the stack in the stack just above the stack fitting through which the horizontal branches discharge into the stack. As can be seen from figures 11 and 12 , the stack 
terminated in a closed chamber or drum supplied with water around its circumference through six pipes 1 in. in diameter. This drum then discharged water through the annular space between the stack wall and the inserted pipe, thus forming the sheet of water representing the sheet that would under service conditions be flowing down the stack from higher floors. By using different diameters for the inserted pipe, the thickness of the sheet of water could be varied, and by changing the pressure in the drum, the velocity of flow in the sheet could be varied. Thus the equipment afforded a means of obtaining much more flexibility in the experiments than could be obtained with an actual stack.

'There is, however, one definite difference between the conditions in the sheet produced artificially and those in the sheet flowing down an actual stack. As has already been pointed out, in an actual stack there will be a very marked velocity gradient at any horizontal section of the sheet, the velocity increasing from zero at the wall to a maximum value at the inner surface of the sheet. This is not true in the artificially produced sheet of water, in which the velocity distribution is probably nearly uniform. This fact will very possibly cause a slight difference in the results obtained in the two cases. Hence certain conclusions based on results obtained with the special setup, were later checked by making tests on an actual stack. Nevertheless, it was much simpler to experiment with the special setup and the range of conditions that could be tested was much greater than with an actual stack. Furthermore, the difference in velocity distributions in the two cases was believed to be a minor consileration.

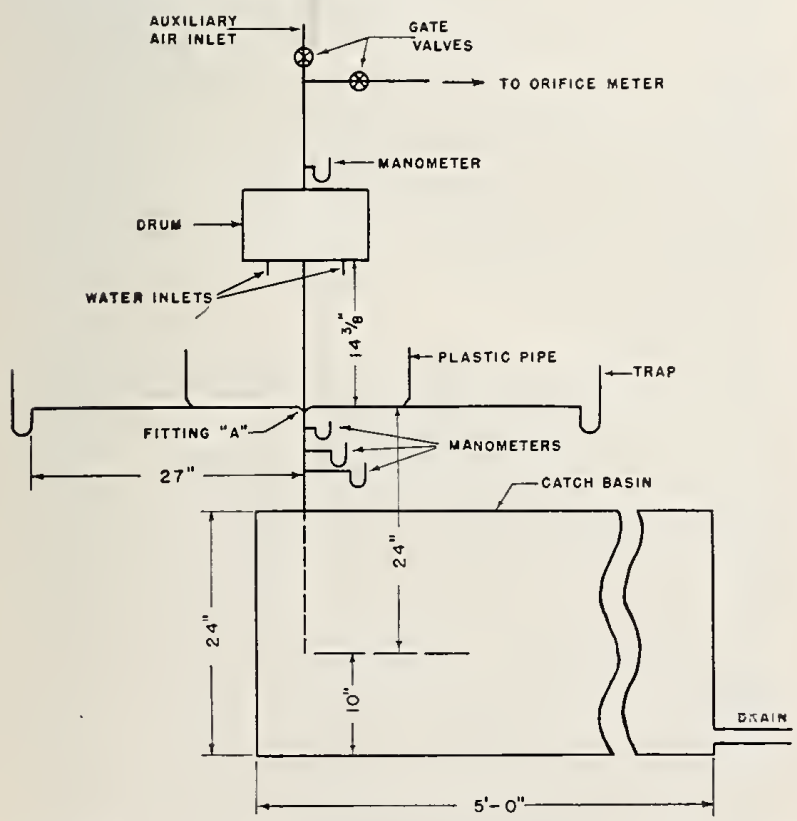

FIGURE 10. Outline drawing of apparatus for simulating flow conditions in stack.

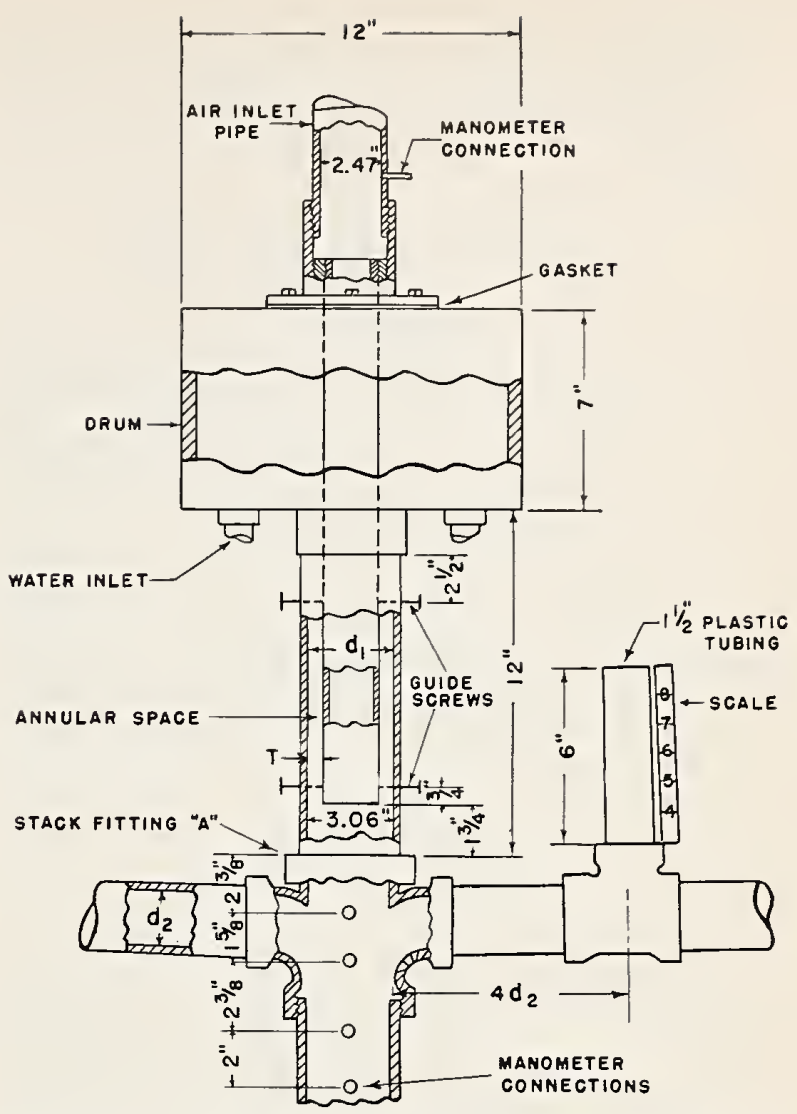

FIGURE 11. Details of apparatus for simulating flow conditions in stack.

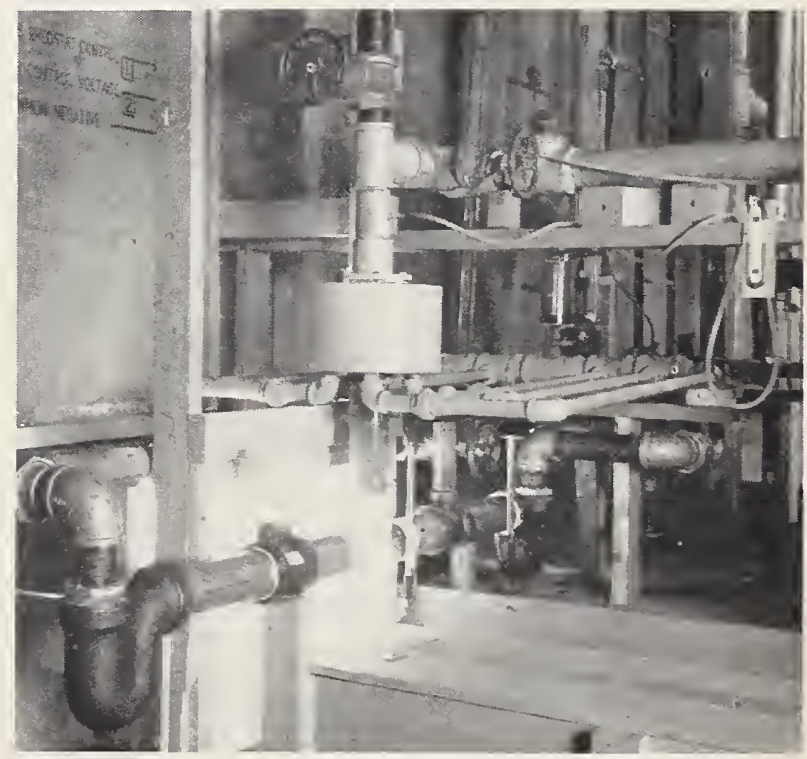

Figure 12. Apparatus for simulating flow conditions in stack. 


\section{Analysis of Conditions at the Stack Fitting Where a Horizontal Drain Empties Into a Stack at an Inter- mediate Floor of a Multistory Build - ing}

\subsection{Statement of the Problem}

Hunter defined the capacity of a stack fitting as the rate of flow in gallons per minute at which water flowing out of the horizontal drain into the stack just begins to build up in the vertical part of the fitting above the inlet branch of the fitting. This definition seems to apply only to the highest horizontal branch on the stack where no water would be coming down the stack from a higher level. Obviously, such a building-up of water would create a backpressure on the drain and would retard the flow from the drain in to the stack.

However, the conditions might be quite different at an intermediate floor of a multistory building. Here the flow from the drain may have to mix with or deflect a high-velocity sheet of water flowing down the stack from the higher floors in order to get into the stack. The act of mixing with the vertically flowing sheet of water or deflecting it will necessarily create a backpressure on the drain whether or not the water builds up in the stack above the level of the drain. This backpressure will be very considerable if the flow down the stack at the level of the horizontal drain under consideration is large and if it has, as it usually would, a relatively high velocity. This would restrict the rate of flow out of the drain and would tend to back up the flow in the fixture drain unduly, unless this fact is taken into consideration in the design of the stack and drain.

The tests carried out in the basic investigation with the special equipment described earlier in this paper constitute the first step in the attempt to furnish the necessary data to make an adequate investigation of this problem and hence to furnish the necessary means for designing a stack and horizontal branches. As has been pointed out already, the tests reported in this paper were made only with sanitary tee stack fittings for a 3 -in. stack, and it appeared desirable to carry out a similar investigation with long-turn $T-Y$ stack fittings, as these are frequently used in the construction of plumbing systems. The tests with these latter fittings have already been made. Although the tests with the long-turn $T-Y$ fittings gave somewhat different backpressures than did those with the sanitary tee fittings, the results with the two types of fittings are consistent with each other.

\subsection{Analysis of the Problem}

The problem will be investigated for the somewhat idealized conditions shown in figure 13. The drain is assumed to connect straight into the stack instead of through a sanitary tee, as it did in the

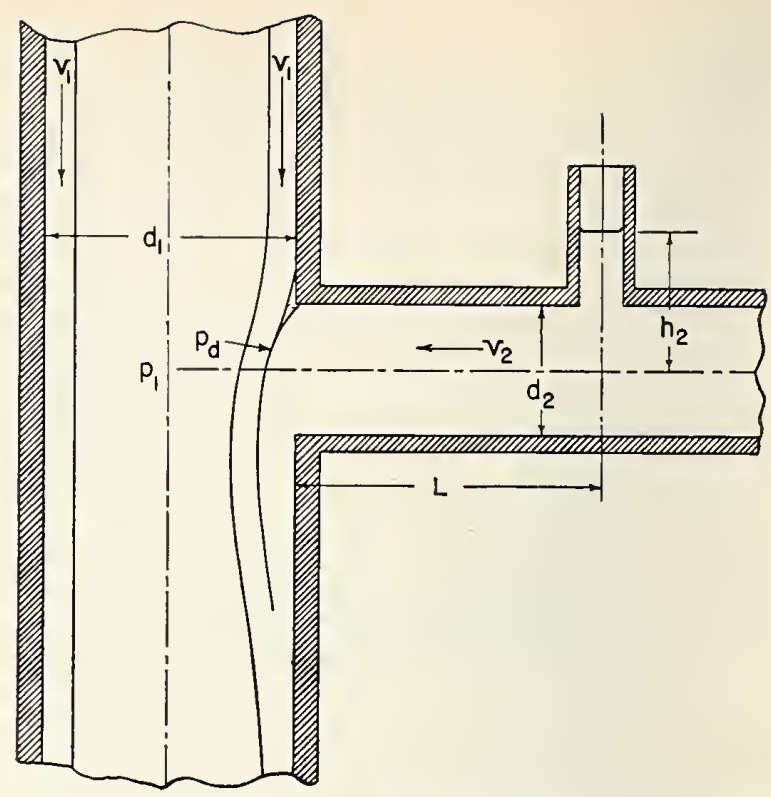

FIgURE 13. Diagrammatic representation of flow from horizontal branch deflecting sheet flow down stack.

tests. The analysis can be made equally well for the actual condition, but it leads to a somewhat more complicated equation, and it was found that any effect of simplifying the conditions merely influenced the empirical coefficient in the equation.

Water is assumed to be flowing down the stack from higher floors in a sheet which, as it approaches the level of the drain under consideration, has the thickness $T$ and has a mean velocity of flow, $v_{1}$. The pneumatic pressure in the core of air at the center of the stack is $p_{1}$, and in most of the tests it was fairly constant and slightly less than atmospheric pressure at a point just above the level of the horizontal branch. Water is assumed to be flowing out of the branch at the volume rate $Q_{2}$, with the mean velocity $v_{2}$, it being assumed throughout the analysis that the branch is flowing full near its entrance into the stack, as it did in the tests. At a distance $L$ along the branch from the stack the head $h_{2}$ corresponding to the pressure $p_{2}$ is measured.

Although it is assumed that the velocity in a horizontal section of the vertical sheet is uniform, this is far from being the case, as has aheady been pointed out in this paper. Actually, a very steep velocity gradient exists, the velocity being zero at the wall and very high in the outer laver. However, this simplifying assumption will be taken into account automatically in the determination of the empirical constants in the equation, and hence the actual velocity distribution will be neglected. The actual conditions in the vertical sheet before it comes in contact with the flow from the branch can be evaluated by investigating the formation of the turbulent boundary layer in the sheet as it flows downward. The equations 
are very complicated, however, and their solution would be very time consuming, so that the increased accuracy resulting from their use would probably not be worth the effort of solving them.

The theoretical analysis of the problem will be based on the equation of momentum, considering the horizontal component of the momentum of the water flowing out of the branch. The simplest approach is to consicler the slug of water between a vertical section through the point at which the pressure $p_{2}$ is measured and the vertical section coinciding with the end of the branch where it enters the stack. The change in momentum of the water in flowing from the upstream section to the downstream section is equal to the sum of the external forces acting axially on the slug of water. This will be put in mathematical form as follows:

The flux of momentum across the upstream section is equal to $\rho ?_{2} v_{2}$, if we assume uniform velocity distribution. As the cross section of the flow is constant between these two sections (we assume that the drain is flowing full), and there is no change in the quantity of water flowing as it passes between the two sections, the flux of momentum across the downstream section is also $\rho ? ?_{2} v_{2}$, again assuming unifor'm velocity distribution.

The external forces acting on the slug of water are (fig. 14):

1. The force due to $p_{2}$, tending to produce flow out of the branch.

2. The force due to $p_{1}$, tending to oppose flow out of the branch.

3. The force due to $p_{d}$, the backpressure caused by the deflection of the sheet of water flowing down the stack by the flow out of the branch, and

4. The frictional resistance in the branch between the two sections, tending to oppose flow out of the branch.

It is assumed that the branch is horizontal, instead of slightly sloping as it would be actually, so that gravitational forces do not have to be considered. Furthermore, if the velocity distribution changes between the two sections considered, there would be a slight change in the flux of momentum between the sections, but this will be neglected here.

Summarizing, we have the force $p_{2} a_{2}$, tending to force the water into the stack. Opposing this we have the pressure forces, $p_{1} a_{2}$ and $p_{d} a_{2}$, together with the friction force, $F=\pi d_{2} L_{\tau_{0}}$, where $\tau_{0}$ is the frictional force per unit area exerted by the walls of the pipe on the slug of water opposing the flow into the stack. Hence

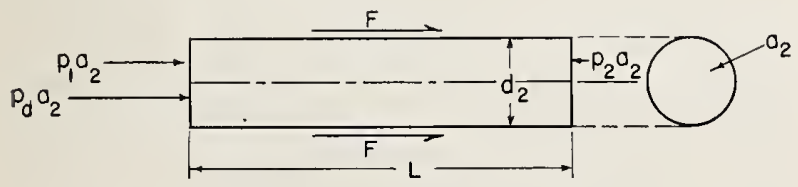

FIGURE 14. External forces acting on slug of water in branch.

$$
\text { or } \begin{aligned}
\rho Q_{2} v_{2}-\rho Q_{2} v_{2} & \left.=\left(p_{1}+p_{d}\right) a_{2}+\pi d_{2} L \tau_{0}-p_{2} a_{2}=0\right) \\
p_{2} a_{2} & =\left(p_{1}+p_{d}\right) a_{2}+\pi d_{2} L \tau_{0} .
\end{aligned}
$$

The friction force can be represented as a backpressure, $p_{f}$, opposing the flow of water out of the branch. Thus

$$
p_{f} a_{2}=\rho g h_{f} a_{2}
$$

and, using the Darcy-Weisbach equation for flow in pipes, we obtain

$$
p_{j} a_{2}=f a_{2} \rho g \frac{L}{d_{2}} \frac{v_{2}^{2}}{2 g},
$$

where $f$ is the Darcy-Weisbach dimensionless friction coefficient. Replacing also the other pressures by their equivalent expression, density times acceleration of gravity times height of water column corresponding to the pressure concerned, we obtain

$$
h_{2}=h_{1}+h_{d}+f \frac{L}{d_{2}} \frac{v_{2}^{2}}{2 g},
$$

which could equally well have been developed from the energy equation, assuming uniform velocity distribution.

All the quantities in eq 27 are known or can be measured except the dynamic head, $h_{d}$. 'The interaction between the vertical sheet of water flow ing in the stack with the flow from the branch is too complicated to analyze, except in a very general and approximate way. In making this analysis, we assume that the flow lines in the vertical sheet of water are changed from straight lines to arcs of circles of radius $r$ by the stream from the branch (fig. 15). Obviously this is a simplifying assumption that probably does not fit the facts exactly, yet it yields results that bring order out of

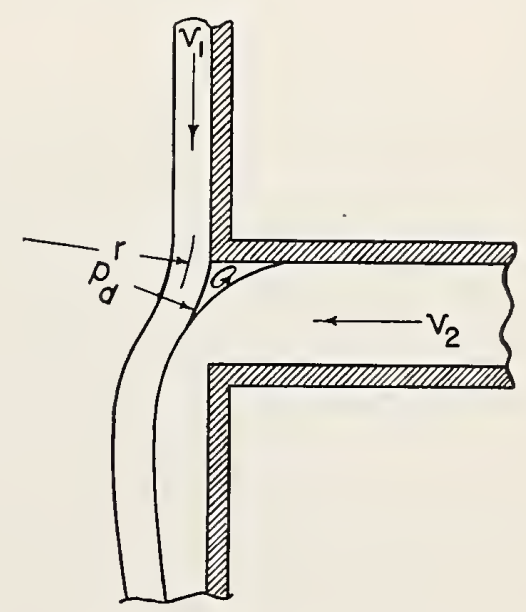

Figure 15. Evaluation of backpressure on branch. 


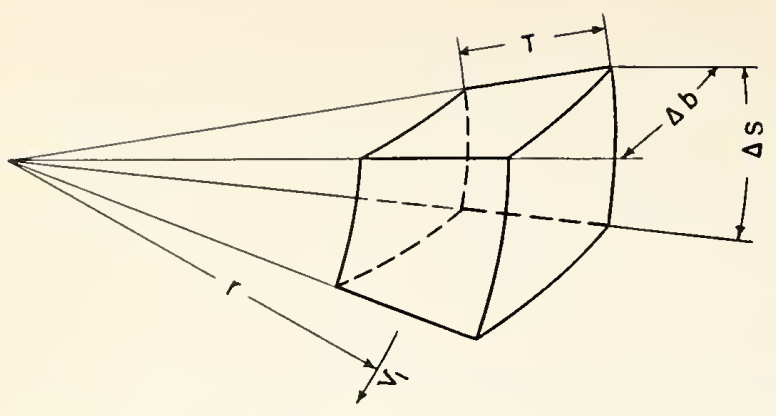

Figure 16. Diagram for evaluating centrifugal force acting on an elementary mass of water moving in a circular path.

the experimental data and hence may be considered justified by that fact.

Under this assumption, we can write the centripetal force, $F_{d}$, which the flow from the branch exerts on the vertical sheet as (fig. 16):

$$
F_{d}=\sum \frac{m v_{1}^{2}}{r}=\sum \frac{\rho T \Delta s \Delta b v_{1}^{2}}{r}
$$

where $m$ is the mass of the elementary volume $\Delta, \Delta b T$. Then

$$
p_{d}=\frac{F_{d}}{\Sigma \Delta s \Delta b}=\rho \frac{T}{r} v_{1}^{2},
$$

if we assume an average value of $r$ for all elementary volumes. It follows then that

$$
h_{d}=\frac{T}{r g} v_{1}^{2}
$$

and, substituting this result in eq 27 , we have

$$
h_{2}-h_{1}=\frac{2 T}{r} \frac{v_{1}^{2}}{2 g}+\frac{f L}{d_{2}} \frac{v_{2}^{2}}{2 g} .
$$

Dividing by $h_{2}-h_{1}$, and rearranging:

$$
\frac{f L}{d_{2}} \frac{v_{2}^{2}}{2 g\left(h_{2}-h_{1}\right)}=1-\frac{2 T}{r} \cdot \frac{r_{1}^{2}}{2 g\left(h_{2}-h_{1}\right)} .
$$

The quantities in eq 32 are all capable of determination by measurement or otherwise, except the radius of curvature of the flow lines. We proceed to consider the quantity $r$ in more detail.

Other things being equal, it may be assumed that $r$ is dircetly proportional to the momentum, $\rho Q_{1} v_{1}$, of the sheet of water flowing down the stack. Likewise, other things being equal, it may be assumed that $r$ is inversely proportional to the momentum, $\rho_{2} v_{2}$, of the flow out of the branch. The validity of these and other assumptions made in evaluating $r$ will be determined by the success that we have in fitting the final equation to the experimental data. In view of the above assumptions, we can write

$$
r=\text { function }\left(\frac{\rho Q_{1} v_{1}}{\rho Q_{2} v_{2}}\right) .
$$

But $r$ must be placed equal to a length times this function if our cquation is to be dimensionally correct, and the dimension that seems to be most closely involved with $r$ is the diameter, $d_{2}$, of the branch. Hence we can write

$$
r=d_{2} \phi\left(\frac{\rho Q_{1} v_{1}}{\rho Q_{2} v_{2}}\right)=d_{2} \phi\left(\frac{a_{1} v_{1}^{2}}{a_{2} v_{2}^{2}}\right),
$$

where $a_{1}$ is the cross-sectional area of the sheet of water in the stack at the level of the branch, and $a_{2}$ is the cross-sectional area of the flow in the branch for the branch flowing full.

\section{Hence}

$$
r=d_{2} \phi\left(4 \frac{\pi d_{1} T v_{1}^{2}}{\pi d_{2}^{2} v_{2}^{2}}\right)=C d_{2} \phi\left(\frac{d_{1}}{d_{2}} \cdot \frac{T}{d_{2}} \cdot \frac{v_{1}^{2}}{v_{2}^{2}}\right)
$$

the constant 4 being absorbed in the coefficient $C$. We go one step further and assume that the function $\phi$ can be taken as a simple power. This was found to be approximately true for the ratio $T / d_{2}$, and hence it should be true for the other two ratios. Thus

$$
\begin{aligned}
r & =C d_{2}\left(\frac{d_{1}}{d_{2}}\right)^{a}\left(\frac{T}{d_{2}}\right)^{a}\left(\frac{v_{1}^{2}}{v_{2}^{2}}\right)^{a} \\
& =C d_{2}\left(\frac{d_{1}}{d_{2}}\right)^{a}\left(\frac{T}{d_{2}}\right)^{a}\left\{\frac{\frac{v_{1}^{2}}{2 g\left(h_{2}-h_{1}\right)}}{\frac{v_{2}^{2}}{2 g\left(h_{2}-h_{1}\right)}}\right\}
\end{aligned}
$$

We now substitute the value of $r$ given by eq 35 in eq 32, writing for simplicity:

$$
\begin{aligned}
& \frac{v_{1}^{2}}{2 g\left(h_{2}-h_{1}\right)}=X, \quad \text { and } \frac{v_{2}^{2}}{2 g\left(h_{2}-h_{1}\right)}=Y: \\
& \frac{f L}{d_{2}^{-}} Y=1-\bar{C} \frac{2 T}{d_{2}\left(\frac{d_{1}}{d_{2}}\right)^{a}\left(\frac{T}{d_{2}}\right)^{a}\left(\frac{X}{Y}\right)^{a}} X,
\end{aligned}
$$

or

$$
\frac{f L}{d_{2}} Y=1-C_{1}\left(\frac{d_{2}}{d_{1}}\right)^{a}\left(\frac{T}{d_{2}}\right)^{1-a} Y^{a} X^{1-a}
$$

Here there are two quantities, $C_{1}$ and $a$, to be determined from the experimental data. It is interesting to note that, before the relation between the exponents of $X$ and $Y$ in the right member of eq 36 had been demonstrated by analysis, it had becn found from a study of the experimental data that the exponent of $Y$ was very close to $3 / 8$, and the exponent of $X$ was very close to $5 / 8$, thus substantiating the relation between these exponents given by eq 36 . 
Before proceeding to the evaluation of $C_{1}$ and $a$, a further discussion regarding details that have not been taken into account in deriving eq 36 will be given. Some of these have already been pointed out, but we are now in a position to consider them more definitely.

It has been assumed that the horizontal branch enters the stack without turning downward slightly, as a sanitary tee fitting actually does. In practice, either a sanitary tee or a long-turn T-Y is used as the stack fitting (see fig. 7, 8 , and 9 for drawings of sanitary tee fittings). Either type of fitting turns the water downward somewhat at the entrance to the stack, the long-turn fitting somewhat more than the sanitary tee. Furthermore, horizontal branches are actually laid on a slight slope instead of being level, as was assumed in developing eq 36 . If these facts are taken into account, three more terms will have to be added to eq 36 . In the first place, the horizontal component of the momentum will not cancel out for the two sections, as the inwarch flux of momentum at the upstream section will be $\rho a_{2} v_{2}^{2}$, whereas at the downstream section the outward flux of momentum will be $\rho a_{2} v_{2}^{2} \cos \beta, \beta$ being the angle through which the stack fitting deflects the water downward. In addition, there will be a gravitational force tending to produce flow out of the branch, this force being due to the additional head between the center line of the branch and the center of the section of the branch opening into the stack. Likewise, if the branch were laid on a slope instead of being horizontal as assumed, the effect of this slope would be taken into account through the addition of a gravitational force just as has been described for the stack fitting. A further loss due to the deflection of the stream of water by the stack fitting is also involved.

Although all these factors would have to be considered in a complete analysis of the problem, it is believed that for our present purpose their effect will be taken care of adequately in the values determined for the empirical constants that will be found from the experimental data. Hence they will not be considered further at this time.

As a preliminary step in determining the a verage value of the coefficient $C_{1}$ and the exponent $a$ in eq 36 , the value of the Darcy-Weisbach $f$ was taken as 0.03 . Inserting this value of $f$ in eq 36 , setting $L / d_{2}$ equal to 4 , as it was in the tests,

$$
\frac{1-0.12 Y}{\left(T / d_{2}\right) X}=C_{1}\left(\frac{d_{2}}{d_{1}}\right)^{a}\left(\frac{d_{2}}{T}\right)^{a}\left(\frac{Y}{\Gamma}\right)^{a}=\alpha .
$$

The experimental data afforded the necessary information for computing $I, Y$, and $T / d_{2}$, and the ralue of $\alpha$ was then computed for each test run from the first member of the equation. The next step was to determine the value of the exponent $a$ of the quantity, $Y / X$. Values of $\alpha$ were plotted against $Y / X^{\prime}$ on logarithmic paper, and the resulting series of straight lines had so nearly a slope of $3 / 8$ that this value was assumed for convenience.

The next step was to dotormine the value of the exponent $a$ of the quantity, $\left(d_{2} / d_{1}\right)\left(d_{2} / T\right)$. Although theory indicated that the three ratios in the right member of the above equation had the common exponent $a$, it was decided to check this from the data. It was not feasible to separate the ratios, $d_{2} / d_{1}$ and $d_{2} / T$ in this procedure, so it was assumed that both had the same exponent. When values of $\alpha$ were plotted against $\left(d_{2} / d_{1}\right)$ $\left(d_{2} / T\right)$, another series of straight lines with a slope very closely equal to $3 / 8$ again resulted. Hence it was concluded that the three ratios all had the same exponent, $3 / 8$. from

Values of $C_{1}$ were then computed for each run

$$
C_{1}=\frac{\alpha}{\left(\frac{d_{2}}{d_{1}}\right)^{3 / 8}\left(\frac{d_{2}}{T}\right)^{3 / 8}\left(\frac{Y}{X}\right)^{3 / 8}}
$$

separately for the runs with double-branch flow and for the runs with single-branch flow. The average value of $C_{1}$ for double-branch flow was a little less than 1.78 , and for single-branch flow it was about 1.80 , showing that, except for two or three runs with large flows from both branches, in which the capacity of the fitting seems to have been exceeded, the same value of $C_{1}$ applies approximately, whether the flow is from one or from both branches. The value 1.78 was adopted for $C_{1}$.

The average deviation of $C_{1}$ from the average value of 1.78 was found to be 0.24 for the doublebranch flow and 0.25 for the single-branch flow. The probable error in $C_{1}$ was computed from the formula:

$$
\text { Probable error }=0.84 \frac{\text { average deviation }}{\sqrt{\text { number of observations }}},
$$

and was found to be 0.03 . Thus the value of $C_{1}$ can be given as

$$
C_{1}=1.78 \pm 0.03
$$

The formula for the probable error assumes that the deviations are wholly due to accidental errors, and hence it does not apply strictly to the data in question. Nevertheless, it seemed desirable to get at least a rough idea of the closeness with which the average value of 1.78 represents the results obtained from tests made under a widely varving set of conditions.

Using the values of $C_{1}$ and $a$ thus determined, we write eq 36 in the form

$$
0.12 Y=1-1.78\left(\frac{T}{d_{2}}\right)^{5 / 8}\left(\frac{d_{2}}{d_{1}}\right)^{3 / 8} Y^{3 / 8} X^{5 / 8}
$$

or

$$
Y=8.33-14.8\left(\frac{T}{d_{2}}\right)^{5 / 8}\left(\frac{d_{2}}{d_{\mathrm{i}}}\right)^{3 / 8} Y^{3 / 8} \mathrm{Y}^{5 / 8}
$$


Equation 38 can be solved for corresponding values of $X$ and $I^{r}$ for any selected values of $\left(T / d_{2}\right)^{5 / 8}\left(d_{2} / d_{1}\right)^{3 / 8}$. This has been done, and the resulting curves are plotted in figure 17 , together with the experimental data, showing how well the data fit the curves resulting from the analysis of the problem. The experimental points fit quite well except for two of the intermediate curves, the points generally lying too low for one curve and too high for the other. In the runs represented by these points, it was noted several times that peculiar pressure conditions existed in the stack in the vicinity of the branch opening.

It must be pointed out here that, theoretically there are certain restrictions on the applicability of eq 38. In the first place, it applies only to stacks in which it can be assumed that the water flows in an annular sheet on the wall of the stack at the level of the horizontal branch under consideration, without an appreciable content of entrained air. Although it is believed that these idealized conditions are not entirely realized in an actual stack, our information regarding the actual conditions is limited, and consequently we shall assume that eq 38 applies to the actual conditions.

Second, eq 38 applics only when sanitary tee fittings are used to connect the horizontal branches to the stack and only when the head, $h_{2}$, exists at a distance of four pipe diameters upstream from the branch outlet. The horizontal branches are assumed to have a roughness expressed by a valuc of the Darcy-Weisbach $f$ of 0.03 . However, as in eq 38 the friction head loss is generally small in comparison to the dynamic backpressure, it is unlikely that under most conditions small variations in $L$ and $f$ would have much effect on the results.

Finally, the data on which eq 38 is based were obtaincel for a 3 -in. stack only. However, the equation should be applicable to stacks of other diameters through the ratio $d_{2} / d_{1}$.

\section{Summary}

The special equipment described in section 7.2 and shown in figures 11 and 12 was used in the tests described earlier, using double sanitary tee drainage fittings. The tests were made with $1 \frac{112-}{2}$, 2-, and 3-in.-diameter horizontal branches, and with thicknesses of the annular sheet of water in the stack of $0.16,0.34$, and $0.58 \mathrm{in}$. These represent nine different conditions for which the pressures and velocities (or rates of flow) werc measured in the stack and the branches.

Preliminary curves were prepared for each rate of flow and thickness of water sheet in the stack, showing the relationship between pressure head and rate of flow in the branch. In order to obtain from these curves the data shown in tables 8 and 9 , several values of the ratio of the pressure drop through the drain to the drain diameter, $\left(h_{2}-h_{1}\right) /$ $d_{2}$, were sclected. Corresponding flow rates (or velocities) and pressure heads in the branches for. each selected value of $\left(h_{2}-h_{1}\right) / d_{2}$ were obtained by interpolation from each of the preliminary curves. The data for tables 8 and 9 could also have been obtained by making the computations for each separate run instead of interpolating from. the curves, but this would have been more laborious and would have made only an insignificant difference in the results.

The data from tests with the approximately equal rates of flow from both branches are shown in table 8. Flows from one branch only are given in table 9. Figure 17 shows a comparison of the experimental data in tables 8 and 9 with the series of curves representing eq 38 .

It is obvious that the data from the experiments with single-branch flow appear to fit the computed curves as well as do the data from the doublebranch flow for all except one of the curves. The reason for this exception has not becn determined. As eq 38 does not take into account variations in the pipe-friction coefficient with variations in the Reynolds number, and as other minor factors arc neglected for the sake of simplicity in the development of this relation, these things may possibly account for some of the inconsistencies of the plot. In addition, certain difficulties in test procedure and measurements of the fluctuating pressures may have caused some irregularities. But, on the other hand, it will be noted that the fit is good for the two extreme curves and does not seem to deviate in any consistent manner from the intermediate curves. Generally the agreement of the data with the computed curves is fairly good if we consider

TAвLE 8. Data from tests with double sanitary tee drainage fittings, 3-in. stack, flow from both branches

\begin{tabular}{|c|c|c|c|c|c|c|c|c|c|}
\hline $\begin{array}{c}\text { Flow } \\
\text { in } \\
\text { each } \\
\text { branch }\end{array}$ & $\begin{array}{l}\text { Stack } \\
\text { flow }\end{array}$ & $\mathrm{T}$ & $d_{2}$ & $h_{2}-h_{1}$ & $v_{1}$ & $v_{2}$ & $\frac{v_{1}^{2}}{2 g\left(h_{2}-h_{1}\right)}$ & $\frac{v_{2}^{2}}{2 g\left(h_{2}-h_{1}\right)}$ & $\begin{array}{l}\text { Symbol } \\
\text { in fig. } 17\end{array}$ \\
\hline$g p m$ & $g p m$ & in. & $i n$. & $f t$. & $f p s$ & fps & & & \\
\hline 5.0 & 98 & 0. 58 & 1. 62 & 0.094 & 6. 92 & 0.78 & 7. 85 & 0.100 & \\
\hline 1.8 & 158 & .58 & 1.62 & .094 & 11.2 & .28 & 21.0 & .013 & \\
\hline 7.4 & 98 & .58 & 1. 62 & .135 & 6.92 & 1.15 & 5.5 & .152 & \\
\hline 3.4 & 158 & .58 & 1.62 & .135 & 11.2 & 0.53 & 14.5 & .032 & \\
\hline 1.8 & 203 & .58 & 1. 62 & .135 & 14.3 & .28 & 23.7 & .010 & \\
\hline 12.2 & 98 & .58 & 1. 62 & .203 & 6.92 & 1. 89 & 3. 67 & .273 & 0 \\
\hline 6.0 & 158 & .58 & 1. 62 & .203 & 11.2 & 0.936 & 9.65 & .067 & \\
\hline 3.8 & 203 & .58 & 1. 62 & .203 & 14.3 & .59 & 15.8 & .027 & \\
\hline 11.2 & 158 & .58 & 1. 62 & .337 & 11.2 & 1. 74 & 5. 80 & .139 & \\
\hline 7.6 & 203 & 58 & 1. 62 & .337 & 14.3 & 1.18 & 9.95 & .064 & \\
\hline 5. 1 & 252 & .58 & 1. 62 & .337 & 17.7 & 0.79 & 14.7 & .029 & \\
\hline 7.8 & 56 & .34 & 1. 62 & .094 & 6.2 & 1. 22 & 6. 30 & .245 & \\
\hline 11.4 & 56 & .34 & 1. 62 & .135 & 6.2 & 1. 78 & 4. 42 & .366 & \\
\hline 5.4 & 98 & .34 & 1,62 & .135 & 10.9 & 0.84 & 13. 6 & .081 & \\
\hline 18.1 & 56 & .34 & 1. 62 & .203 & 6.2 & 2.82 & 2. 94 & .600 & 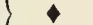 \\
\hline 8.4 & 98 & .34 & 1. 62 & .203 & 10.9 & 1.31 & 9.05 & .131 & \\
\hline 14.8 & 98 & .34 & 1. 62 & .337 & 10.9 & 2.30 & 5.40 & .242 & \\
\hline 9.3 & 137 & .34 & i. 62 & .337 & 15.1 & 1. 45 & 10.5 & .096 & \\
\hline 7.8 & 40 & .16 & 1. 62 & .094 & 8. 75 & 1. 22 & 12.6 & .245 & \\
\hline 12.4 & 40 & .16 & 1. 62 & .135 & 8.75 & 1.93 & 8.85 & .428 & \\
\hline 12.6 & 80 & .16 & 1. 62 & .337 & 17.6 & 1.97 & 14.1 & .178 & 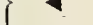 \\
\hline 8.6 & 98 & 16 & 1. 62 & .337 & 21.5 & 1. 34 & 21.2 & .083 & \\
\hline 10.4 & 98 & .58 & 2.06 & .120 & 6.92 & 1.01 & 6. 40 & .130 & \\
\hline 4. 6 & 158 & .58 & 2.06 & .120 & 11.2 & 0.446 & 16.3 & .026 & \\
\hline 17.6 & 98 & .58 & 2.06 & .172 & 6.92 & 1.69 & 4. 32 & .259 & \\
\hline 7.7 & 158 & .58 & 2.06 & .172 & 11.2 & 0.744 & 11.4 & .050 & \\
\hline 31.8 & 98 & .58 & 2.06 & .258 & 6.92 & 3.31 & 2.88 & .560 & \\
\hline 13. 1 & 158 & .58 & 2.06 & .258 & 11.2 & 1. 27 & 7.58 & .096 & $\Delta$ \\
\hline 7.8 & 203 & .58 & 2.06 & .258 & 14.3 & 0.754 & 12.4 & 034 & \\
\hline 245 & 158 & .58 & 2.06 & .429 & 11.2 & 2.37 & 4. 56 & .203 & \\
\hline 16.1 & 203 & .58 & 2. 06 & .429 & 143 & 1. 56 & 7. 46 & .145 & \\
\hline 10. 6 & 252 & .58 & 2.06 & .429 & 17.7 & 1.02 & 11.5 & .037 & \\
\hline
\end{tabular}


TABLE 8. Data from tests with double sanitary tee drainage fittings, 3-in. staek, flow from both branehes-Continued

\begin{tabular}{|c|c|c|c|c|c|c|c|c|c|}
\hline $\begin{array}{l}\text { Flow } \\
\text { in } \\
\text { each } \\
\text { branch }\end{array}$ & $\begin{array}{l}\text { Stack } \\
\text { flow }\end{array}$ & $\mathrm{T}$ & $d_{2}$ & $h_{2}-h_{1}$ & $v_{\mathbf{i}}$ & $v_{2}$ & $\frac{v_{1}^{2}}{2 g\left(h_{2}-h_{1}\right)}$ & $\frac{v_{2}^{2}}{2 g\left(h_{2}-h_{1}\right)}$ & $\begin{array}{l}\text { Symbol } \\
\text { in fig. } 17\end{array}$ \\
\hline $\begin{array}{r}g p m \\
32.4 \\
10.2 \\
5.5 \\
17.8 \\
38.3 \\
19.1 \\
12.3\end{array}$ & $\begin{array}{r}g p m \\
56 \\
98 \\
137 \\
98 \\
98 \\
137 \\
180\end{array}$ & $\begin{array}{l}\text { in. } \\
.34 \\
.34 \\
.34 \\
.34 \\
.34 \\
.34 \\
.34\end{array}$ & $\begin{array}{l}\text { in. } \\
2.06 \\
2.06 \\
2.06 \\
2.06 \\
2.06 \\
2.06 \\
2.06\end{array}$ & $\begin{array}{l}f t . \\
.172 \\
.172 \\
.172 \\
.258 \\
.429 \\
.429 \\
.429\end{array}$ & $\begin{array}{c}f p s \\
6.20 \\
10.9 \\
15.1 \\
10.9 \\
10.9 \\
15.1 \\
19.9\end{array}$ & $\begin{array}{l}f p s \\
3.12 \\
0.983 \\
1.533 \\
1.72 \\
3.69 \\
1.84 \\
1.19\end{array}$ & $\begin{array}{c}3.47 \\
10.7 \\
20.7 \\
7.10 \\
4.27 \\
8.30 \\
14.4\end{array}$ & $\left.\begin{array}{l}.882 \\
.087 \\
.050 \\
.177 \\
.493 \\
.123 \\
.051\end{array}\right)$ & $\nabla$ \\
\hline $\begin{array}{l}15.2 \\
10.2 \\
26.4 \\
13.8 \\
24.8 \\
24.4 \\
16.3\end{array}$ & $\begin{array}{l}40 \\
54 \\
40 \\
54 \\
54 \\
80 \\
98\end{array}$ & $\begin{array}{l}.16 \\
.16 \\
.16 \\
.16 \\
.16 \\
.16 \\
.16\end{array}$ & $\begin{array}{l}2.06 \\
2.06 \\
2.06 \\
2.06 \\
2.06 \\
2.06 \\
2.06\end{array}$ & $\begin{array}{l}.120 \\
.120 \\
.172 \\
.172 \\
.258 \\
.429 \\
.429\end{array}$ & $\begin{array}{c}8.75 \\
11.8 \\
8.75 \\
11.8 \\
11.8 \\
17.6 \\
21.5\end{array}$ & $\begin{array}{l}1.47 \\
0.982 \\
2.55 \\
1.33 \\
2.39 \\
2.36 \\
1.57\end{array}$ & $\begin{array}{c}9.93 \\
18.2 \\
6.91 \\
12.7 \\
8.93 \\
11.2 \\
16.8\end{array}$ & $\left.\begin{array}{l}.288 \\
.125 \\
.585 \\
.160 \\
.344 \\
.201 \\
.090\end{array}\right\}$ & - \\
\hline $\begin{array}{r}61.0 \\
26.9 \\
16.1 \\
7.8 \\
77.0 \\
43.8 \\
25.6 \\
15.5 \\
65.4 \\
44.6 \\
28.3\end{array}$ & $\begin{array}{r}98 \\
158 \\
203 \\
252 \\
98 \\
158 \\
203 \\
252 \\
158 \\
203 \\
252\end{array}$ & $\begin{array}{l}.58 \\
.58 \\
.58 \\
.58 \\
.58 \\
.58 \\
.58 \\
.58 \\
.58 \\
.58 \\
.58\end{array}$ & $\begin{array}{l}3.06 \\
3.06 \\
3.06 \\
3.06 \\
3.06 \\
3.06 \\
3.06 \\
3.06 \\
3.06 \\
3.06 \\
3.06\end{array}$ & $\begin{array}{r}.179 \\
.179 \\
.179 \\
.179 \\
.255 \\
.255 \\
.255 \\
.255 \\
.383 \\
.383 \\
.383\end{array}$ & $\begin{array}{c}6.92 \\
11.2 \\
14.3 \\
17.7 \\
6.92 \\
11.2 \\
14.3 \\
17.7 \\
11.2 \\
14.3 \\
17.7\end{array}$ & $\begin{array}{l}2.71 \\
1.19 \\
0.714 \\
.346 \\
3.42 \\
1.94 \\
1.14 \\
0.687 \\
2.91 \\
1.98 \\
1.25\end{array}$ & $\begin{array}{c}4.15 \\
10.9 \\
17.8 \\
27.9 \\
2.96 \\
7.66 \\
12.5 \\
19.4 \\
5.17 \\
8.37 \\
12.9\end{array}$ & $\left.\begin{array}{l}.635 \\
.123 \\
.032 \\
.011 \\
.713 \\
.229 \\
.078 \\
.029 \\
.143 \\
.064\end{array}\right\}$ & $\square$ \\
\hline $\begin{array}{l}44.8 \\
27.0 \\
69.2 \\
44.6 \\
25.8 \\
73.8 \\
45.0 \\
83.0\end{array}$ & $\begin{array}{r}98 \\
137 \\
98 \\
137 \\
180 \\
137 \\
180 \\
180\end{array}$ & $\begin{array}{l}.34 \\
.34 \\
.34 \\
.34 \\
.34 \\
.34 \\
.34 \\
.34\end{array}$ & $\begin{array}{l}3.06 \\
\text { 3. } 06 \\
3.06 \\
3.06 \\
\text { 3. } 06 \\
\text { 3. } 06 \\
\text { 3. } 06 \\
\text { 3. }\end{array}$ & $\begin{array}{l}.179 \\
.179 \\
.255 \\
.255 \\
.255 \\
.383 \\
.383 \\
.638\end{array}$ & $\begin{array}{l}10.9 \\
15.1 \\
10.9 \\
15.1 \\
19.9 \\
15.1 \\
19.9 \\
19.9\end{array}$ & \begin{tabular}{|l|}
1.98 \\
1.19 \\
3.06 \\
1.97 \\
1.14 \\
3.28 \\
1.99 \\
3.68
\end{tabular} & $\begin{array}{c}10.2 \\
19.8 \\
7.18 \\
13.9 \\
24.1 \\
9.31 \\
16.1 \\
9.66\end{array}$ & $\left.\begin{array}{r}.352 \\
.124 \\
.570 \\
.238 \\
.079 \\
.437 \\
.161 \\
.331\end{array}\right\}$ & 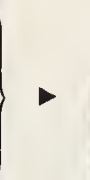 \\
\hline $\begin{array}{l}24.7 \\
38.0 \\
30.0 \\
74.0 \\
43.5 \\
90.0\end{array}$ & $\begin{array}{l}80 \\
80 \\
98 \\
80 \\
98 \\
98\end{array}$ & $\begin{array}{l}.16 \\
.16 \\
.16 \\
.16 \\
.16\end{array}$ & $\begin{array}{l}3.06 \\
3.06 \\
3.06 \\
3.06 \\
3.06 \\
3.06\end{array}$ & $\begin{array}{l}.179 \\
.255 \\
.255 \\
.383 \\
.383 \\
.638\end{array}$ & $\begin{array}{l}17.6 \\
17.6 \\
21.5 \\
17.6 \\
21.5 \\
21.5\end{array}$ & $\begin{array}{l}1.09 \\
1.68 \\
1.33 \\
3.27 \\
1.92 \\
3.96\end{array}$ & $\begin{array}{l}26.8 \\
18.8 \\
28.1 \\
12.5 \\
18.8 \\
11.3\end{array}$ & $\left.\begin{array}{l}.103 \\
.172 \\
.108 \\
.435 \\
.150 \\
.385\end{array}\right\}$ & D \\
\hline $\begin{array}{l}3.6 \\
3.1 \\
5.1 \\
6.1\end{array}$ & $\begin{array}{r}98 \\
137 \\
137 \\
180\end{array}$ & $\begin{array}{l}.34 \\
.34 \\
.34 \\
.34\end{array}$ & $\begin{array}{l}\text { 1. } 62 \\
1.62 \\
1.62 \\
1.62\end{array}$ & $\begin{array}{l}.0945 \\
.135 \\
.203 \\
.338\end{array}$ & $\begin{array}{l}10.9 \\
15.1 \\
15.1 \\
19.9\end{array}$ & $\begin{array}{r}0.562 \\
.482 \\
.799 \\
.951\end{array}$ & $\begin{array}{l}19.4 \\
26.3 \\
17.6 \\
18.2\end{array}$ & $\left.\begin{array}{r}.052 \\
.027 \\
.049 \\
.041\end{array}\right\}$ & $\downarrow$ \\
\hline $\begin{array}{r}5.8 \\
9.2 \\
20.9 \\
15.0 \\
7.0 \\
29.4\end{array}$ & $\begin{array}{l}54 \\
54 \\
40 \\
54 \\
80 \\
54\end{array}$ & $\begin{array}{l}.16 \\
.16 \\
.16 \\
.16 \\
.16 \\
.16\end{array}$ & $\begin{array}{l}1.62 \\
1.62 \\
1.62 \\
1.62 \\
1.62 \\
1.62\end{array}$ & $\begin{array}{l}.0945 \\
.135 \\
.203 \\
.203 \\
.203 \\
.338\end{array}$ & $\begin{array}{c}11.8 \\
11.8 \\
8.76 \\
11.8 \\
17.6 \\
11.8\end{array}$ & $\begin{array}{l}.902 \\
1.43 \\
3.26 \\
2.34 \\
1.09 \\
4.58\end{array}$ & $\begin{array}{c}23.0 \\
16.1 \\
5.85 \\
10.8 \\
23.7 \\
6.40\end{array}$ & $\left.\begin{array}{r}.134 \\
.234 \\
.810 \\
.419 \\
.091 \\
.960\end{array}\right\}$ & 4 \\
\hline 5.5 & 203 & .58 & 2. 06 & .172 & 14.3 & 0.347 & 18.6 & .011 & $\Delta$ \\
\hline $\begin{array}{r}11.0 \\
5.7 \\
9.9 \\
6.1\end{array}$ & $\begin{array}{r}56 \\
98 \\
137 \\
180\end{array}$ & $\begin{array}{l}.34 \\
.34 \\
.34 \\
.34\end{array}$ & $\begin{array}{l}2.06 \\
2.06 \\
2.06 \\
2.06\end{array}$ & $\begin{array}{l}.120 \\
.120 \\
.258 \\
.258\end{array}$ & $\begin{array}{c}6.20 \\
10.9 \\
15.1 \\
19.9\end{array}$ & $\begin{array}{l}1.06 \\
0.550 \\
.956 \\
.589\end{array}$ & $\begin{array}{c}4.98 \\
15.7 \\
13.8 \\
23.8\end{array}$ & $\left.\begin{array}{l}.146 \\
.039 \\
.056 \\
.021\end{array}\right\}$ & $\nabla$ \\
\hline $\begin{array}{r}6.3 \\
11.2 \\
7.3\end{array}$ & $\begin{array}{l}80 \\
80 \\
98\end{array}$ & $\begin{array}{l}.16 \\
.16 \\
.16\end{array}$ & $\begin{array}{l}2.06 \\
2.06 \\
2.06\end{array}$ & $\begin{array}{l}.172 \\
.258 \\
.258\end{array}$ & $\begin{array}{l}17.6 \\
17.6 \\
21.5\end{array}$ & $\begin{array}{l}.610 \\
1.08 \\
0.705\end{array}$ & $\begin{array}{l}27.8 \\
18.6 \\
27.8\end{array}$ & $\left.\begin{array}{l}.034 \\
.071 \\
.030\end{array}\right\}$ & - \\
\hline
\end{tabular}

TABLE 9. Data from tests with double sanitary tee drainage fittings, 3-in. staek, one-braneh flow

\begin{tabular}{|c|c|c|c|c|c|c|c|c|c|}
\hline $\begin{array}{c}\text { Flow } \\
\text { in } \\
\text { each } \\
\text { branch }\end{array}$ & $\begin{array}{l}\text { Stack } \\
\text { flow }\end{array}$ & $\mathrm{T}$ & $d_{2}$ & $h_{2}-h_{1}$ & $v_{1}$ & $v_{2}$ & $\frac{v_{1}^{2}}{2 g\left(h_{2}-h_{1}\right)}$ & $\frac{v_{2}^{2}}{2 g\left(h_{2}-h_{1}\right)}$ & $\begin{array}{l}\text { Symbol } \\
\text { in fig. } 17\end{array}$ \\
\hline$g p m$ & $g p m$ & in. & in. & $f t$ & $f p s$ & $f p s$ & & & \\
\hline 5.40 & 98 & 0.58 & 1. 62 & 0.094 & 6.92 & 0.841 & 7.85 & 0.116 & \\
\hline 2. 70 & 158 & .58 & 1.62 & .094 & 11.2 & .419 & 21.1 & .029 & \\
\hline 8.40 & 98 & .58 & 1.62 & .135 & 6.92 & 1.32 & 5.50 & .197 & \\
\hline 4. 40 & 158 & .58 & 1.62 & .135 & 11.2 & 0.686 & 14.5 & .054 & \\
\hline 2.60 & 203 & .58 & 1. 62 & .135 & 14.3 & .405 & 23.7 & .019 & \\
\hline 13.6 & 98 & .58 & 1.62 & .203 & 6. 92 & 2.31 & 3. 67 & .409 & \\
\hline 7.10 & 158 & .58 & 1.62 & .203 & 11.2 & 1.11 & 9.65 & .094 & 0 \\
\hline 4. 40 & 203 & .58 & 1.62 & .203 & 14.3 & 0.685 & 15.8 & .036 & \\
\hline 29.0 & 98 & .58 & 1.62 & .337 & 6.92 & 4.52 & 2.20 & .936 & \\
\hline 12.9 & 158 & .58 & 1.62 & .337 & 11.2 & 2.01 & 5.80 & .136 & \\
\hline 8.4 & 203 & .58 & 1.62 & .337 & 14.3 & 1. 31 & 9.45 & .078 & \\
\hline 5.7 & 252 & .58 & 1.62 & .337 & 17.7 & 0.890 & 14.65 & .036 & \\
\hline
\end{tabular}

TABLE 9. Data from tests with double sanitary tee drainage fittings, 3-in. stack, one-branch flow-Continued

\begin{tabular}{|c|c|c|c|c|c|c|c|c|c|}
\hline $\begin{array}{l}\text { Flow } \\
\text { in } \\
\text { cach } \\
\text { branch }\end{array}$ & $\begin{array}{l}\text { Stack } \\
\text { flow }\end{array}$ & $\mathrm{T}$ & $d_{2}$ & $h_{2}-h_{1}$ & $v_{1}$ & $v_{2}$ & $\frac{v_{1}^{2}}{2 g\left(h_{2}-h_{1}\right)}$ & $\frac{v_{z^{2}}}{2 g\left(h_{2}-h_{1}\right)}$ & $\begin{array}{l}\text { Symbol } \\
\text { in fig. } 17\end{array}$ \\
\hline$g p m$ & $g p m$ & in. & $i n$. & $f t$. & $f p s$ & $f p s$ & & & \\
\hline 8. 1 & 56 & .34 & 1.62 & .094 & 6.20 & 1.26 & 6.30 & .261 & \\
\hline 3.2 & 98 & .34 & 1.62 & .094 & 10.9 & 0.500 & 19.4 & .041 & \\
\hline 10.8 & 56 & .34 & 1.62 & .135 & 6. 20 & 1.68 & 4. 42 & .324 & \\
\hline 4.8 & 98 & .34 & 1.62 & .135 & 10.9 & 0.749 & 13.6 & 065 & 0 \\
\hline 17. 8 & 56 & 34 & 1.62 & .203 & (6. $2^{0}$ & 2. 2.77 & 2. 94 & .588 & \\
\hline 7.8 & 98 & .34 & 1.62 & .203 & 10.9 & 1.16 & 9.05 & .113 & \\
\hline 14. 2 & 98 & .34 & 1. 62 & .337 & 10.9 & 2.21 & 5.4 & .224 & \\
\hline 8.4 & 137 & .34 & 1.62 & .337 & 15.1 & 1. 31 & 10.5 & .079 & . \\
\hline 7.80 & 40 & .16 & 1. 62 & .094 & 8.75 & 1.22 & 12.6 & .234 & \\
\hline 4. 60 & 54 & 16 & 1.62 & .094 & 11.8 & 0.734 & 23.1 & .089 & \\
\hline 12.5 & 40 & .16 & 1. 62 & .135 & 8.75 & 1.94 & 8.85 & .436 & \\
\hline 8. 10 & 54 & .16 & 1.62 & .135 & 11.8 & 1. 26 & 16.1 & $\begin{array}{l}.183 \\
.\end{array}$ & $\triangleleft$ \\
\hline 6.80 & 80 & .16 & 1.62 & .203 & 17.6 & 1.06 & 23.6 & .091 & \\
\hline 12.3 & 80 & .16 & 1. 62 & .337 & 17.6 & 1.87 & 14.2 & .160 & \\
\hline 8.50 & 98 & .16 & 1.62 & . 337 & 21.5 & 1.32 & 21.2 & .080 & \\
\hline 8. 80 & 98 & .58 & 2.06 & .120 & 6.92 & 0.849 & 6. 40 & .093 & \\
\hline 4. 20 & 158 & .58 & 2.06 & .120 & 11.2 & .405 & 16.3 & .021 & \\
\hline 14.8 & 98 & .58 & 2.06 & .172 & 6.92 & 1.43 & 4. 32 & .184 & \\
\hline 7.1 & 158 & .58 & 2.06 & .172 & 11.2 & 0.686 & 11.4 & .043 & \\
\hline 26.4 & 98 & .58 & 2.06 & .258 & 6. 92 & 2.55 & 2.88 & .391 & $\triangle$ \\
\hline 12.1 & 158 & .58 & 2.06 & .258 & 11.2 & 1.17 & 7.57 & .082 & $\Delta$ \\
\hline 7. 50 & 203 & .58 & 2.06 & .258 & 14.3. & 0. 698 & 12.4 & .029 & \\
\hline 24.0 & 158 & .58 & 2. 06 & .429 & 11.2 & 2.32 & 4. 56 & .195 & \\
\hline 15.7 & 203 & .58 & 2.06 & .429 & 14.3 & 1. 47 & $\begin{array}{l}7.00 \\
7.46\end{array}$ & .079 & \\
\hline 10.4 & 252 & .58 & 2.06 & .429 & 17.7 & 1.01 & 11.5 & $.037)$ & \\
\hline 7.30 & 98 & .34 & 2.06 & .120 & 10.9 & 0.708 & 15.7 & .065 & \\
\hline 25.6 & 56 & .34 & 2.06 & .172 & 6. 20 & 2.47 & 3. 47 & .551 & \\
\hline 11.4 & 98 & .34 & 2.06 & .172 & 10.9 & 1.09 & 15.6 & .109 & \\
\hline 5. 50 & 137 & .34 & 2.06 & .258 & 15.1 & 0.529 & 20.7 & .025 & \\
\hline 18.4 & $\begin{array}{r}138 \\
98\end{array}$ & $\begin{array}{l}.34 \\
.34\end{array}$ & 2.06 & $\begin{array}{r}.420 \\
.429\end{array}$ & $\begin{array}{l}10.1 \\
10.9\end{array}$ & $\begin{array}{l}1.789 \\
1.78\end{array}$ & 7. 10 & .190 & $\nabla$ \\
\hline 35.2 & 98 & .34 & 2.06 & .429 & 10.9 & 3.42 & 4.27 & .421 & \\
\hline 20.2 & 137 & .34 & & .429 & 15.1 & $\begin{array}{l}1.95 \\
1.95\end{array}$ & 8.30 & .138 & \\
\hline 14.0 & 180 & .34 & 2.06 & .429 & 19.9 & 1. 35 & 14.4 & .066 & \\
\hline 9.0 & 54 & .16 & 2.06 & .120 & 11.8 & 0.866 & 18.2 & .097) & \\
\hline 21. 0 & 40 & .16 & 2.06 & .172 & 8.75 & 2.03 & 6.91 & .371 & \\
\hline 13.6 & 54 & .16 & 2.06 & .172 & 11.8 & 1.31 & 12.8 & .156 & \\
\hline 41.8 & 40 & .16 & 2.06 & .258 & 8.75 & 4.04 & 4.61 & .978 & 0 \\
\hline 23.6 & 54 & .16 & 2.06 & .258 & 11.8 & 2.28 & 8.42 & .312 & $\Delta$ \\
\hline 11.2 & 80 & .16 & 2.06 & .258 & 17.6 & 1. 09 & 18.6 & .071 & \\
\hline 23.0 & 80 & .16 & 2.06 & .429 & 17.6 & 2. 20 & 11.2 & .179 & \\
\hline 16.3 & 98 & .16 & 2.06 & .429 & 21.5 & 1.57 & 16.8 & .090 & \\
\hline 24.8 & 158 & .58 & 3.06 & . 179 & 11.2 & 1. 10 & 10.9 & $.104)$ & \\
\hline 16.0 & 203 & .58 & 3.06 & .179 & 14.3 & 0.708 & 17.9 & .043 & \\
\hline 8.2 & 252 & .58 & 3.06 & .179 & 17.7 & $\begin{array}{l}.360 \\
\end{array}$ & 27.7 & .012 & \\
\hline 35.8 & 158 & .58 & & .255 & 11.2 & 1. 58 & 7. 66 & .153 & \\
\hline 25.7 & 203 & .58 & 3.06 & .255 & 14.3 & 1. 14 & 12.5 & .079 & 口 \\
\hline 16.0 & 252 & .58 & 3.06 & .255 & 17.7 & 0.707 & 19.4 & .030 & 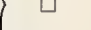 \\
\hline 42.0 & 203 & .58 & 3.06 & .383 & 14.3 & 1.86 & 8.37 & .140 & \\
\hline 28.8 & 252 & .58 & 3.06 & .383 & 17.7 & 1. 27 & 13.0 & .066 & \\
\hline 83.7 & 203 & .58 & 3.06 & .638 & 14.3 & 3. 80 & 5.02 & .333 & \\
\hline 54.7 & 252 & .58 & 3.06 & .638 & 17.7 & 2. 42 & 7.77 & $.143 /$ & \\
\hline 35.6 & 98 & .34 & 3.06 & .179 & 10.9 & 1. 58 & 10.2 & $.216)$ & \\
\hline 24.3 & 137 & .34 & 3.06 & .179 & 15.1 & 1. 0 & 19. 9 & .101 & \\
\hline 59.2 & $\begin{array}{r}98 \\
98\end{array}$ & .34 & 3.06 & .255 & 10.9 & $\begin{array}{l}1.08 \\
2.62\end{array}$ & 7. 18 & .419 & \\
\hline 34.3 & 137 & .34 & 3.06 & .255 & 15.1 & 1.52 & 13.9 & .141 & $\triangleright$ \\
\hline 22.3 & 180 & .34 & 3.06 & .255 & 19.9 & 0.988 & 24.1 & .059 & $\nabla$ \\
\hline 53.2 & 137 & .34 & 3. 06 & .383 & $\begin{array}{l}15.8 \\
15.1\end{array}$ & $\begin{array}{l}\text { 2. } 360 \\
\text { 2. }\end{array}$ & 9. 31 & 228 & \\
\hline 37.7 & 180 & .34 & 3.06 & .383 & 19.9 & 1. 67 & 16.1 & .113 & \\
\hline 69.4 & $\begin{array}{l}180 \\
180\end{array}$ & .34 & 3.06 & .638 & $\begin{array}{l}19.9 \\
19.9\end{array}$ & 3. 06 & 9.66 & .229 & \\
\hline 27.8 & 80 & .16 & 3.06 & .179 & 17.6 & 1. 23 & 26.7 & . 131 & \\
\hline 415 & 80 & .16 & 3.06 & & 17.6 & 1. & & .206 & \\
\hline 31.5 & 98 & .16 & 3.06 & .255 & 21.5 & 1.40 & 28.1 & .119 & \\
\hline 70.5 & 80 & .16 & 3.06 & .383 & 17.6 & 3.12 & 12. 6 & $.396\}$ & D \\
\hline 49.8 & 98 & .16 & 3.06 & .383 & 21.5 & 2.20 & 18. 8 & .198 & \\
\hline 106.0 & 98 & .16 & 3.06 & .638 & 21.5 & 4. 69 & 11.2 & .536 & \\
\hline 3.2 & 137 & .34 & 1.62 & .135 & 15.1 & 0.500 & 26. & ] 029. & \\
\hline 47 & 137 & 34 & 1.62 & .203 & 15.1 & .73 & 17,6 & .041 & $\diamond$ \\
\hline 5.9 & 180 & .34 & 1.62 & .337 & 19.9 & .916 & 18.2 & .0381 & \\
\hline 27.9 & 54 & .16 & 1.62 & . 337 & 11.8 & 4. 36 & 6.40 & .872 & $\triangleleft$ \\
\hline 0.9 & 203 & .58 & 2.06 & . 120 & 14.3 & 0.087 & 26.6 & $.001\}$ & $\Delta$ \\
\hline 3.4 & 203 & .58 & 2.06 & .172 & 14. 3 & .328 & 18.6 & $.010\}$ & \\
\hline 14.2 & 56 & .34 & 2.06 & . 120 & 6. 20 & 1.37 & 4.97 & .243 & \\
\hline 2.7 & 137 & .34 & 2.06 & .120 & 15.1 & 0.26 & 29.7 & .00 & 7 \\
\hline 10.2 & 137 & .34 & 2.06 & .258 & 15.1 & .985 & 13.8 & .058 & $\checkmark$ \\
\hline 6.2 & 180 & .34 & 2.06 & .258 & 19.9 & .599 & 23.8 & $.022\}$ & \\
\hline 7.4 & 98 & .16 & 2. 06 & .258 & 21.5 & .715 & 27.9. & .031 & 0 \\
\hline
\end{tabular}




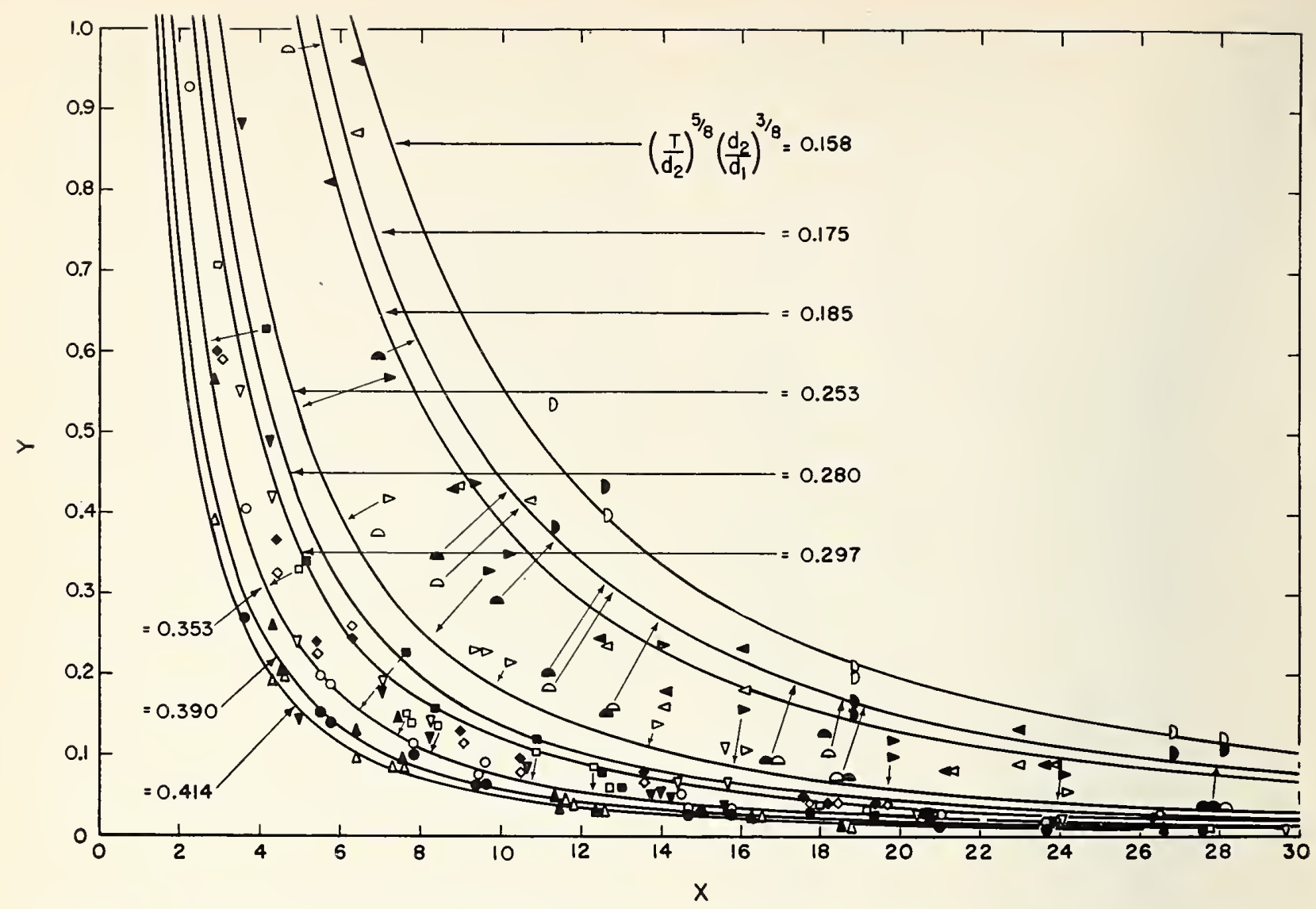

FIGURE 17. Results of tests to determine backpressures in horizontal branches due to interference of flow down stack and flow from branches (3-inch stack).

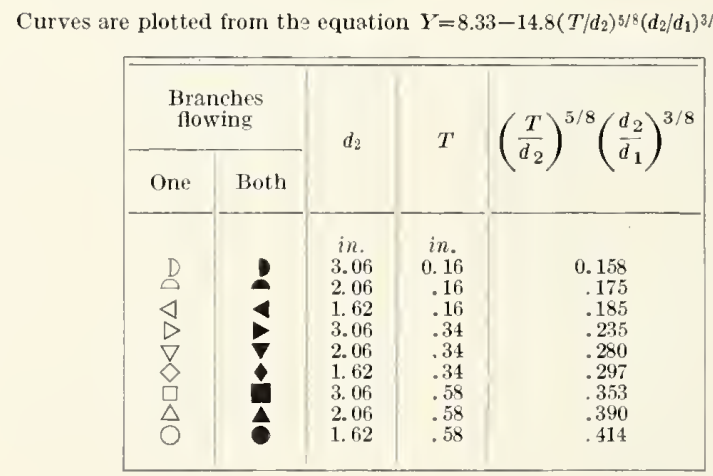

the difficulty of measuring fluctuating pressures, and the fact that eq 38 is necessarily approximate in its nature and contains experimentally determined constants.

A few tests were made in which the rates of flow from the branches were evidently sufficient to fill the stack at the point of entrance, after which a slight increase in flow from the branch caused a large increase in backpressure. It cannot be expected that eq 38 will apply when this condition is attained.

These data from 3-in. branches are shown in figure 18. It is noteworthy that the above- mentioned phenomena occurred to a noticeable extent only when 3 -in. branches were used with the 3-in. stack. The reason for this is simply that, for a given velocity of flow in a horizontal branch, a large branch delivers more water than a smaller one, and, if the velocity is great enough, the large branch will cause the stack to be completely filled at the point of water entrance, whereas a smaller branch will not cause the stack to be filled. Equation 38 indicates that for a given thickness of the sheet of water and velocity of flow in the stack, and for a given magnitude of the backpressure, large branches will deliver more water to the stack 


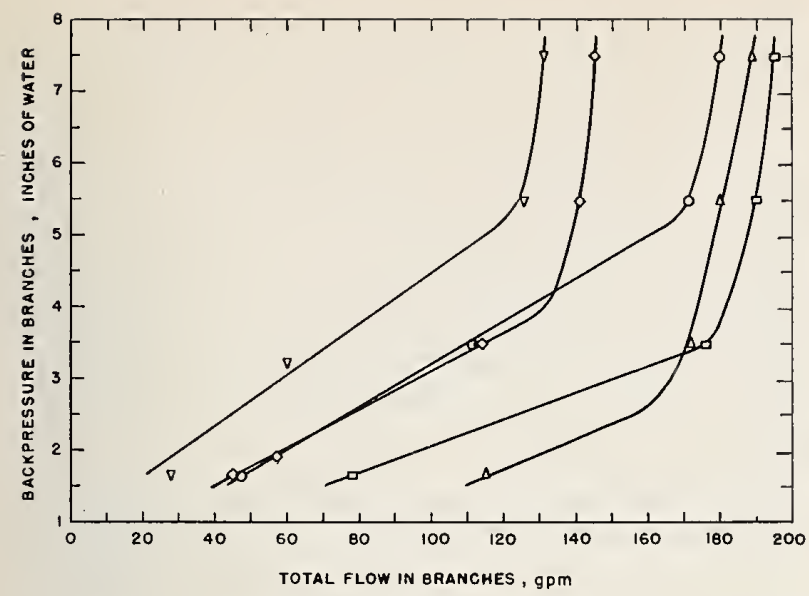

Figure 18. Effect of backpressures in horizontal branches when the capacity of the stack is reached.

Diameter of stack, 3 inches. Stack fitting used was a $3 \times 3 \times 3 \times 3$-inch double sanitary tfe. Pncumatic pressure reduction in stack was 0.3 inch of water column below atmospheric pressure. Flow rates in the two branches approximately equal.

\begin{tabular}{|c|c|c|}
\hline Flow in stack & $\begin{array}{c}\text { Thickness, } T, \\
\text { of water shect }\end{array}$ & Symbol \\
\hline$g p m$ & $i n$. & \\
98 & 0.34 & $\square$ \\
137 & .34 & $\bigcirc$ \\
98 & .58 & $\triangle$ \\
158 & .58 & $\diamond$ \\
303 & .58 & $\nabla$ \\
\hline
\end{tabular}

than smaller ones. This was found to be true in tests made in this investigation. It also suggests that, for a given condition of flow in the stack and a given backpressure in the branch, large branches are more likely to fill the stack than smaller ones.

Figure 19 shows large flows from both horizontal branches (123 gpm total) interfering with a still larger flow (145 gpm) down the stack and shows the large backpressure caused by this interference. The total flow from the two branches in this illustration was approximately equally divided between the two branches, although it appears that the flow from the right-hand branch was a little greater than the flow from the left-hand branch. The data were not taken with a high degree of accuracy as the photograph was intended merely as an illustration of the phenomenon, not as a means of obtaining data.

The shadows in figure 19 indicate that the entire section of the stack was filled just below the level of the branches and that a mass of water was thrown upward by the impact of the streams of water meeting in the center of the cross section of the stack.

It is likely that this effect of an additional backpressure on the branch due to the stack becoming almost or completely filled at the branch level would have to be considered in an accurate analysis of the problem. It has been neglected here for the sake of simplicity, and, as it occurs only in the largest branch size and then only to a limited

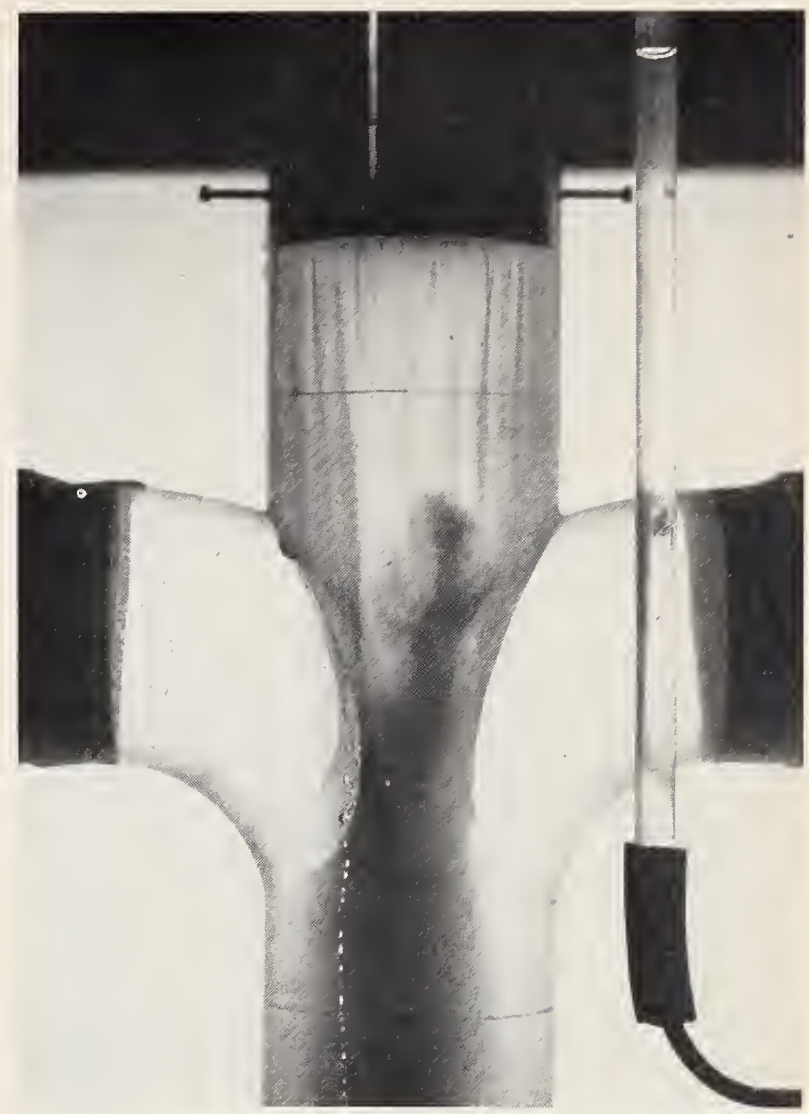

Figure 19. Backpressure produced in a branch when the stack fitting is filled at the branch level by flows from the two branches meeting the flow down the stack.

Total flow in both branches is 123 gallons per minute. Flow in stack is 145 gallons per minute.

extent for any reasonable velocity of flow, it probably did not affect very much of the data. On the other hand, for two of the three curves in figure 17 that do not fit the experimental data very well, this additional backpressure due to the tendency of the stack to be filled existed to a limited extent, hence may account for some of the scatter.

Another possible reason why two of the computed curves in figure 17 applying to the 3 -in. branches do not agree well with the experimental data is that in these two cases there existed a considerable negative pneumatic pressure in the stack a few inches below the branch opening, although just above the branch openings the pneumatic pressure was nearly a tmospheric. This again was probably due to the stack being filled or nearly filled at the branch level, resulting in the air flow past the fitting being seriously restricted. The reduced pressure below the fitting may have been transmitted to some extent to the cross section of the branch opening, so that the actual pneumatic pressure acting on the branch outlet would have been somewhat less than that indicated br the readings just above the fitting. If this latter factor weie taken into account, the effect would be 
to move the experimental data in the direction of the computed curves in figure 17. However, it appears extremely difficult to actually apply this correction numerically as it is not known just what the mean value of the pneumatic pressure acting on the branch opening was. Possibly the answer is that no combination of flows in the stack and from the branch should be permitted that will allow the stack to fill sufficiently to produce these extreme changes in pressure near the branch opening. This points to the necessity of giving more attention to what Hunter called the fitting capacity.

\section{Application of the Results of the Investigation}

Now that a relation has been developed involving the pressures, velocities of flow, and the diameters of the stack and of the horizontal branches emptying into the stack, we may well ask what practical application of this relation can be made in designing plumbing svstems and in preparing loading tables. What follows should be considered merely as some preliminary suggestions as to how the results can be utilized. Later information and further study of the results may conceivably modify the views expressed here as there has not been an opportunity as yet to test fully the applications of the results of the paper.

There are two main steps involved in applying the results of this investigation to the design of vertical stacks and horizontal branches for any given system. The first step is the determination of the maximum rates of flow that can be permitted to occur simultaneously in the stack and in a horizontal branch at any given point on the stack, from the standpoint of back pressure produced thereby in the horizontal branch. Information given in this paper allows this to be done for a stack in which sanitary tee fittings are used to connect the horizontal branches to the stack, if we assume what maximum backpressure is to be permitted in the horizontal branches.

The second step in the design process involves the application of the theory of probability in arriving at the number of fixture units that can be permitted on the stack and on any horizontal branch without probably exceeding the permissible simultaneous rates of flow from the branch and in the stack at the given branch level more than a selected portion of the time. Or, to put the matter in another way, we wish to determine what diameters of stack and branch must be used in order to take care adequately of simultaneous flows that probably will not be exceeded more than a given portion of the time from the stack and its branches. For a multistory building this is a complicated problem in compound probabilities, and no analysis appears to have been made of it as yet.

Important as is Hunter's application of the theory of probability to the determination of probable loads [12,13], it had to do with over-all loads on the entire system or some given part of the system and does not apply to the probable flow distribution between different parts of the system. We still have the problem of determining what combinations of flow probably will occur not more than a given portion of the time at a given branch level in a multistory building when this flow is considered in two parts, the first comprising the flow coming down the stack from higher levels and comprising the flow from a number of horizontal branches, the second being the flow from the particular horizontal branch that is being considered.

The assumption made at the outset in developing the relation under discussion - that the drain or branch is flowing full at the outlet-requires some consideration as, in general, a fixture drain that flows full at the outlet may subject the fixture trap on it to serious self-siphonage effects if it is only stack-vented. As the present discussion relates to large buildings, that is, buildings with large numbers of fixtures, we assume that the horizontal branches entering the stack have a considerable number of fixtures connected to them and that they are back-vented, loop-vented, or otherwise adequately vented. This being the case, the fact that the horizontal branch to which the fixtures are attached may flow full at its outlet need not necessarily have any serious effects as far as self-siphonage is concerned.

In order to make eq 38 more convenient to use, we replace $v_{2}$ in terms of $Q_{2}$ and $d_{2}, v_{1}$ in terms of $Q_{1}$ and $d_{1}$, and eliminate $T$. Using the relation

$$
Q_{2}=\frac{\pi d_{2}^{2}}{4} v_{2}
$$

replacing $T_{t}$ by its value from eq 13 , and $v_{\ell}$ from eq $15 \mathrm{~b}$, we obtain

$$
\begin{aligned}
& \frac{Q_{2}^{2}}{\left(h_{2}-h_{1}\right) d_{2}^{4}}=331-26.4 \frac{Q_{1}^{7 / 8}}{d_{1}^{5 / 4} \cdot d_{2}^{7 / 4}} \cdot \frac{Q_{2}^{3 / 4}}{h_{2}-h_{1}}, \quad(39 \mathrm{a}) \\
& \text { or } \quad Q_{2}^{2} \\
& \frac{Q_{2} g\left(h_{2}-h_{1}\right) d_{2}^{4}}{2}=5.13-8.83 \frac{g^{3 / 16}}{k_{\varepsilon}^{1 / 16}} \cdot \frac{Q_{1}^{7 / 8}}{d_{1}^{5 / 4}} \cdot \frac{Q_{2}^{3 / 4}}{2 g\left(h_{2}-h_{1}\right) d_{2}^{7 / 4}} \cdot
\end{aligned}
$$

All of the quantities in eq $39 \mathrm{~b}$ are expressed in foot-second-units, and the equation is applicable only when the sheet of water is traveling at terminal velocity, when the pressure head, $h_{2}$, is measured at a distance of 4 diameters from the stack, and when a sanitary tee stack fitting is used. 'This means that the assigned value of $h_{2}-h_{1}$ used in preparing a working diagram, such as that shown in figure 20 , would be for a point 4 diameters away from the stack. A slight effect due to friction and slope would have to be taken into account if we consider points further from the stack than this, and this could be computed from the standard pipe-flow equation for full pipes. 


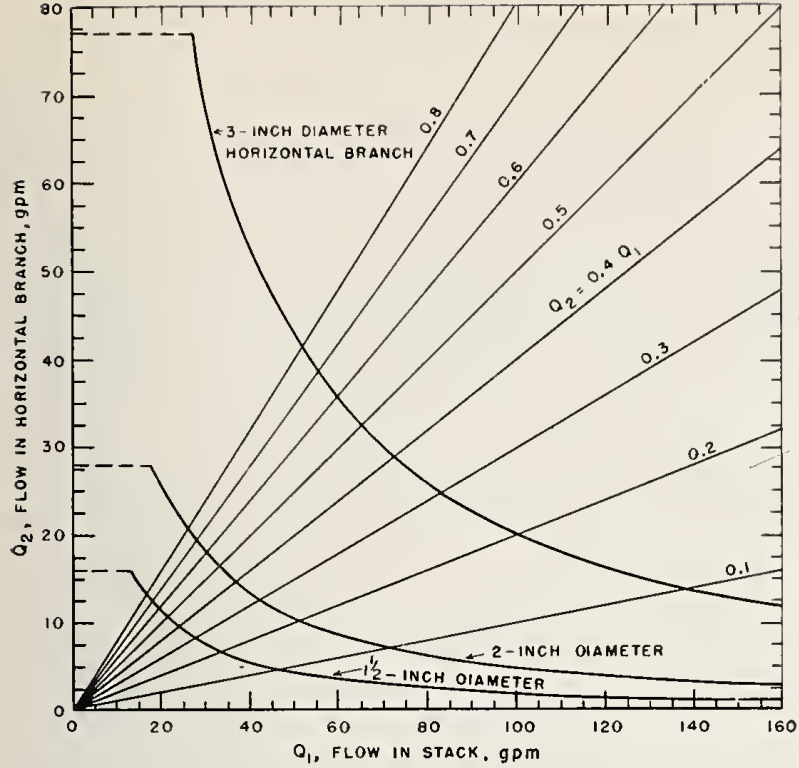

Figure 20. Permissible flow combinations at the junction of a horizontal branch and a 3-inch stack.

The curves shown for $b 1$ anch diameters of $11 / 2,2$, and 3 inches represent eq $39 \mathrm{~b}$ when the branches are flowing just full but under no pressure $\left(h_{2}-h_{1}=0.5 d_{2}\right)$ at a distance of 4 drain diameters from the stack and when sanitary tee drainage fittings are used to connect the stack and the horizontal branches.

The dashed lines show the computed rates of flow which would cause the

hy dashed lines show the computed rates cf flow which would cause
hydient in a horizontal branch to equal 14 inch per foot.

But as the alteration of eq $39 \mathrm{a}$ or $39 \mathrm{~b}$ to include this factor would cause the equation to be more complicated, and as this effect can be taken into account by assigning a limiting value to the rate of branch flow that will result in a friction loss per unit length of branch equal to or somewhat less than the slope of the branch, we are justified in using eq 39a and $39 \mathrm{~b}$ as they are derived, at least for our present purposes.

Equation $39 \mathrm{~b}$ can be solved for $Q_{2}$ in terms of $Q_{1}$ for a chosen value of $h_{2}-h_{1}$ and for selected values of stack and branch diameters. Such a solution for a 3 -in. stack is shown in figure 20 superposed on a series of straight lines that represent the branch flow as various fractional parts of the flow in the stack above the branch level under consideration.

The curved lines in figure 20 are plotted from eq $39 \mathrm{~b}$ and give the corresponding flows in the stack and in a single horizontal branch for an assumed pressure difference between the stack and a point in the branch 4 branch diameters back from the stack, $h_{2}-h_{1}=0.5 d_{2}$. The straight lines, $Q_{2}=Q_{1}$, enable one to read directly the ratio of $Q_{2}$ to $Q_{1}$.

A modification of this plot, in which $Q_{2}$ is plotted against $Q_{1}+Q_{2}$, would enable one to determine the limiting ratios of branch flow to flow in the stack just below the branch conncetion at any branch level. Trial computations indicate that such a procedure will not serve to furnish the actual design but will rather furnish a series of limiting values of the ratio $Q_{2} / Q_{1}$, or $Q_{2} /\left(Q_{2}+Q_{1}\right)$, which must not be exceeded. Other considerations will be involved in the actual design, and these require further study.

Another matter that requires investigation is the suitability of the assumption that the upper limit of the head, $h_{2}-h_{1}$, should be taken as $0.5 d_{2}$. This is equivalent to letting a horizontal branch flow just full near its junction with the stack, providing the pneumatic pressure in the stack is the same as that in a vent connecting to the horizontal branch. If the pneumatic pressure in the stack is less than in the vent, the drain will flow less than full, and if grcater the drain will flow under a slight head. However, it seems reasonable that under most conditions the pnenmatic pressures in vented horizontal branches will not be greatly different from the pncumatic pressures in the stack where the horizontal branches connect. In vicw of this assumption and of the fact that eq $39 \mathrm{~b}$ is applicable only where a horizontal drain flows full at its connection to the stack, and as it does not appcar that such a horizontal branch flowing just full for a small fraction of the time could result in adverse effects, it scems reasonable to set the limiting valuc of $h_{2}-h_{1}$ equal to $0.5 d_{2}$. Furthermore, in the actual design of a system it would be anticipated that this limit would be reached for only a small fraction of the time, and that the head would be smaller for the major portion of the time owing to probability considerations.

At this time it must be pointed out that eq $39 \mathrm{a}$ and $39 \mathrm{~b}$ are subject to the same limitations as those stated previously for $\mathrm{eq} 38$, as $\mathrm{eq} 39 \mathrm{a}$ and $39 \mathrm{~b}$ are based on eq 38 . In addition, the latter equations are, at least theoretically, applicable only for stacks having a roughncss cxpressed by a valuc of $k_{s}$ of 0.00083 , corresponding to new cast-iron soil pipe. Any cffect due to roughness will depend on its effect on the terminal velocity and terminal length. According to cqs $15 \mathrm{~b}$ and 22 , the effect of roughness on terminal velocity and terminal length is inversely proportional to the $1 / 10$ and $1 / 5$ powers of the roughness factor, $k_{s}$, respectively. Hence it would appear that for the range of roughness encountered in commonly used stack matcrials, there would be only a small difference in the computed terminal velocities and terminal lengths due to different degrees of roughness.

Another possible logical criterion for the maximum permissible flow in a horizontal branch under any condition is to permit no flow in the branch greater than that which results in a friction loss that will make the hydraulic gradient steeper than the slope of the branch, such a limit to be cxceeded not more than a sclected fraction of the time. If this is done, the static pressure head in the branch will nowherc be greater than at a point near the stack. If this limit is exceeded, excessive pressures may develop in the branch at some distance from the stack for high rates of flow. For long horizontal branches loaded witls a number of 
fixtures, this could result in sluggish drainage and possible backwater effects or overflow of certain low-set fixtures such as bathtubs or shower stalls, and would be likely to reduce the effectiveness of vents connecting to the horizontal branch.

One other point that deserves consideration here is the effect of hydrestatic heads in small, short horizontal branches receiving the discharge from only a few fixtures, such as a 2-in. horizontal branch to which the waste pipes from a combination sink-and-laundry tray fixture, a washbasin. and a bathtub are connected. It can be shown that a reasonable probability exists for the simultaneous discharge of two of these fixtures, and that the corresponding flow rate could very well exceed that resulting in a bydraulic gradient equal to the slope of the branch. Yet it is generally conceded that in a small installation, such as that described above, no harmful effects are experienced due to this fact. 'Thus it might at first appear that the above-mentioned criterion is unwarranted. Probably, in all fairness, it should be admitted that flows in such a horizontal branch as that discussed here may be allowed to exceed somewhat those indicated by the above criterion, at least in single family dwellings, owing to the fact that the maximum flows and pressures occur in the horizontal branch at such a point and at such times that it is not likely that any harm may be done. However, in larger and longer horizontal branehes loaded with a larger number of fixtures, and where there may be several such branches at different levels connecting to a soil staek, it is easy to think of situations where certain fixtures might be subjected to adverse hydraulic and pneumatic effects should the horizontal branches be flowing for an appreciable portion of the time under an excessive hydraulic gradient, or an excessive hydrostatic backpressure, even if the branch were vented. Hence for large systems it would appear that criteria of the nature suggested above are necessary. In this connection, it would probably have been better for illustrative purposes to have prepared figure 20 for a stack larger than 3 in. in diameter as figure 20 indicates horizontal-branch flow limits that, under certain conditions, are lower than are known to be satisfactory from a practical viewpoint, for the reasons stated above. However, as eq 39 was derived on the basis of tests made on a 3 -in.-diameter stack, figure 20 was prepared for this diameter of staek, and will, for the present, suffice for illustration of the basic principles involved in determining limiting flow combinations at the point of junction between a horizontal branch and a stack. Granting that eq $39 \mathrm{~b}$ is applicable to larger diameters of stack through the ratio $d_{2} / d_{1}$, figure 20 could just as well have been prepared for a larger stack.

\section{Conclusions}

The terminal velocity of a sheet of water flowing' down the wall of a vertical pipe, providing the thickness of the sheet is small compared with the diameter of the pipe, can be computed from the formula

$$
v_{t}=3.0\left(Q_{1} / d_{1}\right)^{2 / 5},
$$

$v_{t}=$ the terminal velocity in feet per second

$Q_{1}=$ the rate of flow in gallons per minute

$d_{1}=$ the diameter of the stack in inches.

2 . The distance through which a sheet of water flowing down the wall of a vertical pipe must fall before attaining approximately its terminal velocity can be computed from the formula $L_{t}=0.052 v_{t}^{2}$, where $L_{t}$ is the terminal length in feet, and $v_{t}$ is the terminal velocity in feet per second.

3. Stack capacity is elosely related to horizontal branch capacity, and the two must be considered together.

4. The pneumatic pressures in the stack and the terminal velocity of the sheet of water flowing down the stack influence stack capacity. Thus the whole design of the building stack and building drain and the submergence or nonsubmergence of the building sewer affect stack capacity, particularly in installations that are inadequately vented, or in which the building drain or building sewer is inadequate for one reason or another.

5. The principal contribution of the present paper to the problem of capacities of stacks and horizontal branches is in the development of what appears to be a new and important additional limiting criterion. In this connection, the following criterion is proposed. The capacity of a drainage stack at the level of any horizontal branch is defined as the total flow at that level which causes a preassigned positive pressure in the horizontal branch that cannot be relieved by venting or, in the case of horizontal branches low on the stack, by increasing the size of the building drain.

6. Based on information contained in this paper, it appears that the ideal solution to the problem of maximum loadings on stacks and horizontal branches would have to satisfy three requirements, at least for the major portion of the time during which the fixtures on the system are in congested or frequent use. The three conditions that should be satisfied for the selected fraction of the time are:

(a) The total load on a stack nust not be so great as to cause the stack to flow more than one-fourth to one-third full wherever terminal velocity exists. According to both Hunter and Dawson, this limit is necessary in order to prevent undue noise, vibration, and pressure fluctuations, and in order to allow the satisfactory functioning of vents connecting to the lower portions of the stack.

(b) No horizontal branch shall be loaded so heavily as to cause the hydraulic gradient to exceed the slope of the drain, or to cause the stack to be completely filled where the branch discharges into it. 
(c) At any point of connection of a horizontal branch to a stack no simultaneous combination of flows in the stack and in the horizontal branch shall occur that cause the horizontal branch to flow under an excessive hydrostatic head, or backpressure. A logical limit would appear to be that of allowing a horizontal branch to be loaded no more heavily than to result in its flowing just full near its junction with the stack. Equation 39b may be used to determine various flow combinations that give this result. The reasons for this requirement, of course, are similar to those given under (b) above.

In connection with the preceding discussion, Hunter's experimental studies and his application of the thcory of probability to the problem afford an approximate method of determining the fixtureunit loadings that would satisfy points (a) and (b). However, in order to determine maximum fixture-unit loadings that would satisfy point (c), it will first be necessary to develop an application of the theory of probability dealing with the probable combinations of flow resulting from the random discharges of two separate groups of plumbing fixtures, one group being those on a particular horizontal branch, and the other being those draining into the stack from all higher levels. Until this problem is solved it will be impossible to realize the full utility of the investigation reported in this paper.

7. In some cases the limiting load on the stack at a given point may very well be determined by noise and vibration considerations, or by pressure fluctuations, rather than by backpressure on the branches. In other cases, the size or nature of the venting system or the diameter of the house drain may be the limiting factor in determining the practical capacity of the stack.

\section{Further Investigation}

The results obtained in this investigation represent but a single step toward a solution of the problem of stack capacities. The tests involved the use of a sanitary tee stack fitting. Similar tests made with long-turn T-Y stack fittings, which are also quite commonly used, have been completed since this paper was started, and these results are consistent with those presented in this paper. Similarly, as the tests made with the apparatus shown in figures 10,11 , and 12 do not simulate in all details the conditions of flow in actual drainage systems, the tests have been repeated with an actual stack. The results obtained with this stack (which are, in general, consistent with the results reported in this paper) will be published at a later date.

Other data obtained include measurements of terminal velocities, variation in air content radi- ally through the sheet of water, and pneumatic pressures in the stack just below the point of cutry of water from the branch.

Acknowledgment is marle to the Housing and Home Finance $\Lambda$ gency for its support of the investigation reported licre. John L. French contributed a number of useful ideas, including the idea of using the special apparatus for simulating the sheet flow down the stack. Vincent 'l'. MTanas gave the authors much useful arlvice in conncction with planning the investigation. Otto Hintz carried out much of the laborious computation involved. Lewis A. Lembeck was responsible for the conduct of the tests with the assistance of Edward J. Norcome, and the results are due in no small measure to their careful and thorough work.

\section{References}

[1] Sherman M. Woodward and Chesley J. Posey, The hydraulies of steady flow in open channels (John Wiley \& Sons, Inc., New York, N. Y., 1941).

[2] Recommended minimum requirements for plumbing in dwellings and similar buildings; Final Report of the Subcommittee on Plumbing of the Building Code Committee, U. S. Department of Commerce, Elimination of Waste Series, BH2 (1924).

[3] Recommended minimum requirements for plumbing, revision of the above, $\mathrm{BH} 13$ (1932).

[4] Plumbing manual, NBS Building Materials and Structures Report BMS66, Report of the Subcommittee on Plumbing of the Central Housing Committee on Research, Design, and Construction (1940).

[5] F. M. Dawson and A. A. Kalinske, Report on hydraulies and pneumatics of plumbing drainage systems, I., University of Iowa Studies in Engineering, Bulletin $10(1937)$.

[6] F. M. Dawson and A. A. Kalinske, Report on the hydraulics and pneumatics of the plumbing drainage system, Technical Bulletin 2 of the National Association of Master Plumbers of the United States, Washington, D. C. (1939).

[7] Harold E. Babbitt, Tests on the hydraulies and pneumatics of house plumbing, Engineering Experiment Station Bulletin No. 143, University of Illinois, XXI, No. 47 (July 21, 1924).

[8] Roy B. Hunter, Gene E. Golden, and Herbert N. Eaton; Cross-connections in plumbing systems, NBS J. Research 20, 479 (1938) RP1086.

[9] Garbis H. Keulegan, Laws of turbulent flow in open channels, NBS J. Research $\mathbf{2 1}, 707$ (1938) RP1151.

[10] Roy B. Hunter, unpublished manuscript, National Bureau of Standards.

[11] Hunter Rouse, Elementary mechanics of fluids, p. 211 (John Wiley \& Sons, Inc., New York, N. Y., 1946).

[12] Roy B. Hunter, Methods of estimating loads in plumbing systems, NBS Building Materials and Structures Report BMS65 (1940).

[13] Herbert N. Eaton and John L. French, Fixture unit ratings as used in plumbing system design, Housing Research Paper 15, Housing and Home Finance Agency (1951).

[14] Garbis H. Kenlegan, Friction losses in short pipes and culverts; unpublished manuscript, National Bureau of Standards (1948). 


\section{Appendix. Evaluation of the Sand Roughness Coefficient, $\boldsymbol{k}_{\boldsymbol{s}}$}

TABLE 10. Computation of the sand roughness coefficient, $k_{s}$ from Hunter's data [10] on friction losses for new cast-iron soil pipe flowing full

\begin{tabular}{|c|c|c|c|c|c|}
\hline $\begin{array}{c}\text { Nominal } \\
\text { diameter }\end{array}$ & $\begin{array}{c}\text { Actual } \\
\text { diameter }\end{array}$ & $f$ & $8 / f$ & $\sqrt{8 / f}$ & $\log _{10} R$ \\
\cline { 2 - 3 } in. & in. & & & & \\
2 & 2.06 & 0.0301 & 267 & 16.35 & 0.0128 \\
3 & 2.90 & .0258 & 310 & 17.60 & .176 \\
4 & 3.93 & .0243 & 329 & 18.15 & .301 \\
5 & 4.85 & .0250 & 320 & 17.90 & .398 \\
\hline
\end{tabular}

In table $10, f$ is the Darcy-Weisbach friction coefficient, and $R$ is the radius of the pipe. From an unpublished paper by Keulegan [14], we have $\sqrt{8 / f}=4.75-2.5\left(k_{s} / R\right)+5.75\left(1+k_{s} / R\right){ }^{2} \log _{10}\left(1+R / k_{s}\right)$.

As $k_{s} / R$ is very small

$$
\sqrt{8 / f}=4.75-5.75 \log _{10}\left(R / k_{8}\right) .
$$

Now if we plot the data in the last two columns of table 10 , fair a curve through the points, and extend the curve back to the point, $\log R=0$, corresponding to $R=1$ in., we can solve the last equation for $k_{s}$ by substituting the value read from the plot for $\sqrt{8 / k_{s}}$ :

whence

$$
\begin{gathered}
16.24=4.75-5.75 \log _{10} k_{s}, \\
\log _{10} k_{s}=-2.00
\end{gathered}
$$

and

$$
k_{s}=0.010 \mathrm{in.,} \text { or } 0.00083 \mathrm{ft} \text {. }
$$

Washington, September 4, 1951. 


\section{BUILDING MATERIALS AND STRUCTURES REPORTS}

\section{[Continued from cover page $\mathrm{x}$ ]}

BMS36 Structural Properties of Wood-Frame Wall, Partition, Floor, and Roof Constructions With "Red Stripe" Lath Sponsored by The Weston Paper and Manufac-

turing Co
Structural Properties of Two "Dunstone" Wall Constructions Sponsored by the
W. E. Dunn Manufacturing Co
Structural Properties of a Wall Construction of "Pfeifer Units" Sponsored by the

Structural Properties of Two "Dunstone" Wall Constructions Sponsored by the
W. E. Dunn Manufacturing Co
Structural Properties of a Wall Construction of "Pfeifer Units" Sponsored by the

BMS38

Wisconsin Units Co
Structural Properties of Wood-Frame Wall and Partition Construction with "Celotex"

BMS42 Insulating Boards Sponsored by The Celotex Corporation
formance

BMS43

BMS44

Performance Test of Floor Coverings for Use in Low-Cost Housing: Part 2

BMS47

Structural Properties of Prefabricated Wood-Frame Constructions for Walls, Par-

titions, and Floors Sponsored by American Houses, Inc.
Structural Properties of "Precision-Built" Frame Wall and Partition Constructions

BMS48 Sponsored by the Homasote Co.

BMS49

BMS50

Metallic Roofing for Low-Cost House Construction

Stability of Fiber Building Boards as Determined by Accelerated Aging

BMS51

BMS52

Structural Properties of "Tilecrete Type A" Floor Construction Sponsored by the Tilecrete Co

Effect of Ceiling Insulation Upon Summer Comfort Sponsored by the Munlock Engineering Co

BMS53

BMS54

BMS55

BMS58

BMS59

BMS60

BMS61

BMS62

Effect of Soot on the Rating of an Oil-Fired Heating Boiler.

Effects of Wetting and Drying on the Permeability of Masonry Walls

Strength of Soft-Soldered Joints in Copper Tubing

Properties of Adhesives for Floor Coverings Bricks Produced in the United States

Structural Properties of Two Nonreinforced Monolithic Concrete Wall Constructions.- 10

Structural Properties of a Precast Joist Concrete Floor Construction Sponsored by the Portland Cement Association.

Moisture Condensation in Building Walls

Solar Heating of Various Surfaces_._.

Methods of Estimating Loads in Plumbing Systems

Plumbing Manual Partitions, Floors, and Roofs, Sponsored by Herman A. Mugler

BMS

BMS65

BMS66

BMS67

BMS68

BMS69

BMS70

BMS71

BMS72

BMS73

BMS74

Performance Test for Floor Coverings for Use in Low-Cost Housing: Part 3....

Stability of Fiber Sheathing Boards as Determined by Accelerated Aging

Asphalt-Prepared Roll Roofings and Shingles

Fire Tests of Wood- and Metal-Framed Partitions

Structural Properties of "Precision-Built, Jr." Prefabricated Wood-Frame Wall Construction Sponsored by the Homasote Co

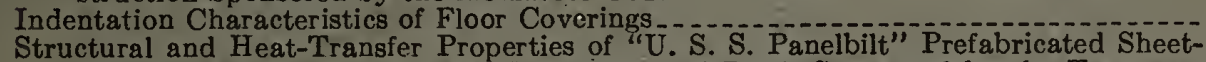
Steel Constructions for Walls, Partitions, and Roofs Sponsored by the Tennessee Coal, Iron \& Railroad Co...

BMS75

BMS76

BMS77

BMS78

BMS79

BMS80

BMS81

BMS82

BMS83

BMS84

BMS85

BMS86

Survey of Roofing Materials in the North Central States

Properties and Performance of Fiber Tile Boards

Structural, Heat-Transfer, and Water-Permeability Properties of Five Earth-Wall Constructions

Water-Distributing Systems for Buildings

Performance Test of Floor Coverings for Use in Low-Cost Housing: Part 4

Field Inspectors' Check List for Building Constructions (cloth cover, 5 × 7 Z/z Inches) --

Water Permeability of Walls Built of Masonry Units

Strength of Sleeve Joints in Copper Tubing Made With Various Lead-Base Solders...

Survey of Roofing Materials in the South Central States. With Changes in Relative Humidity and Temperature .

Structural, Heat-Transfer, and Water-Permeability Properties of "Speedbrik" Wall Construction Sponsored by the General Shale Products Corporation

BMS87 A Method for Developing Specifications for Building Construction-Report of Subcommittee on Specifications of the Central Housing Committee on Research,
Design, and Construction.

BMS89

Structural Properties of "Precision-Built, Jr." (Second Construction) Prefabricated

Wood-Frame Wall Construction Sponsored by the Homasote Co
Structural Properties of "PHC" Prefabricated Wood-Frame Construction for Walls,

BMS90

Floors, and Roofs Sponsored by the PHC Housing Corporation...

BMS92

Fire-Resistance Classifications of Building Constructions 
[Continued from cover page III]

BMS94 Water Permeability and Weathering Resistance of Stucco-Faced, Gunite-Faced, and "Knap Concrete-Unit" Walls

BMS95

BMS96

BMS97

BMS98

BMS99

BMS100

BMS101

BMS102

BMS103

BMS104

Tests of Cement-Water Paints and Other Waterproofings for Unit-Masonry Walls

Properties of a Porous Concrete of Cement and Uniform-Sized Gravel

Experimental Dry-Wall Construction With Fiber Insulating Board...

Physical Properties of Terrazzo Aggregates "Mul and Heat-Transfer Properties of "Multiple Box-Girder Plywood Panels" for Walls, Floors, and Roofs

BMS105

BMS106

BSM108

BMS109

BSM110

BMS111

BMS112

Relative Slipperiness of Floor and Deck Surfaces

Strength and Resistance to Corrosion of Ties for Cavity Walls

Painting Steel

Measurements of Heat Losses From Slab Floors

Structural Properties of Prefabricated Plywood Lightweight Constructions for Walls, Partitions, Floors, and Roofs Sponsored by the Douglas Fir Plywood Association

Paint Manual With Particular Reference to Federal Specifications

Laboratory Observations of Condensation in Wall Specimens

Temperature Distribution in a Test Bungalow With Various Heating Devices...... 106

Strength of Houses: Application of Engineering Principles to Structural Design

Paints for Exterior Masonry Walls_.........

Performance of a Coal-Fired Boiler Converted to Oil

Properties of Some Lightweight-Aggregate Concretes With and Without an Airentraining Admixture

BMS113

BMS114

BMS115

BMS116

BMS117

BMS118

BMS119

BMS120

Fire Resistance of Structural Clay Tile Partitions

Temperature in a Test Bungalow With Some Radiant and Jacketed Space Heaters..-

A Study of a Baseboard Convector Heating System in a Test Bungalow

Preparation and Revision of Building Codes

Fire Resistance of Walls of Lightweight Aggregate Concrete Masonry Units

Stack Venting of Plumbing Fixtures... Aggregate Concrete Masonry Units

Wet Venting of Plumbing Fixtures

Fire Resistance of Walls of Gravel-Aggregate Concrete Masonry Units

Investigation of Failures of White-Coat Plasters

BMS121

BMS122

BMS123

BMS124

BMS125

BMS126

Physical Properties of Some Samples of Asbestos-Cement Siding

Fire Tests of Wood-Framed Walls and Partitions With Asbestos-Cement Facings...-

Fire Tests of Steel Columns Protected With Siliceous Aggregate Concrete.

Stone Exposure Test Wa

BMS127

BMS128

BMS120

The Self-Siphonage of Fixture Traps

Effect of Aging on the Soundness of Regulariy Hydrated Dolomitic Lime Putties.

Atroospheric Exposure Tests of Nailed Sheet Metal Building Materials

BMS130

BMS131

Fire Endurance of Shutters for Moving-Stairway Openings

Methods and Equipment for Testing Printed-Enamel Felt-Bose Flor Coving

BMS132

Fire Tests of Gunite Slabs and Partitions

Capacities of Plumbing Stacks in Buildings

${ }^{106}$

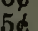

.


